\title{
NIOSH Deepwater Horizon Roster Summary Report
}

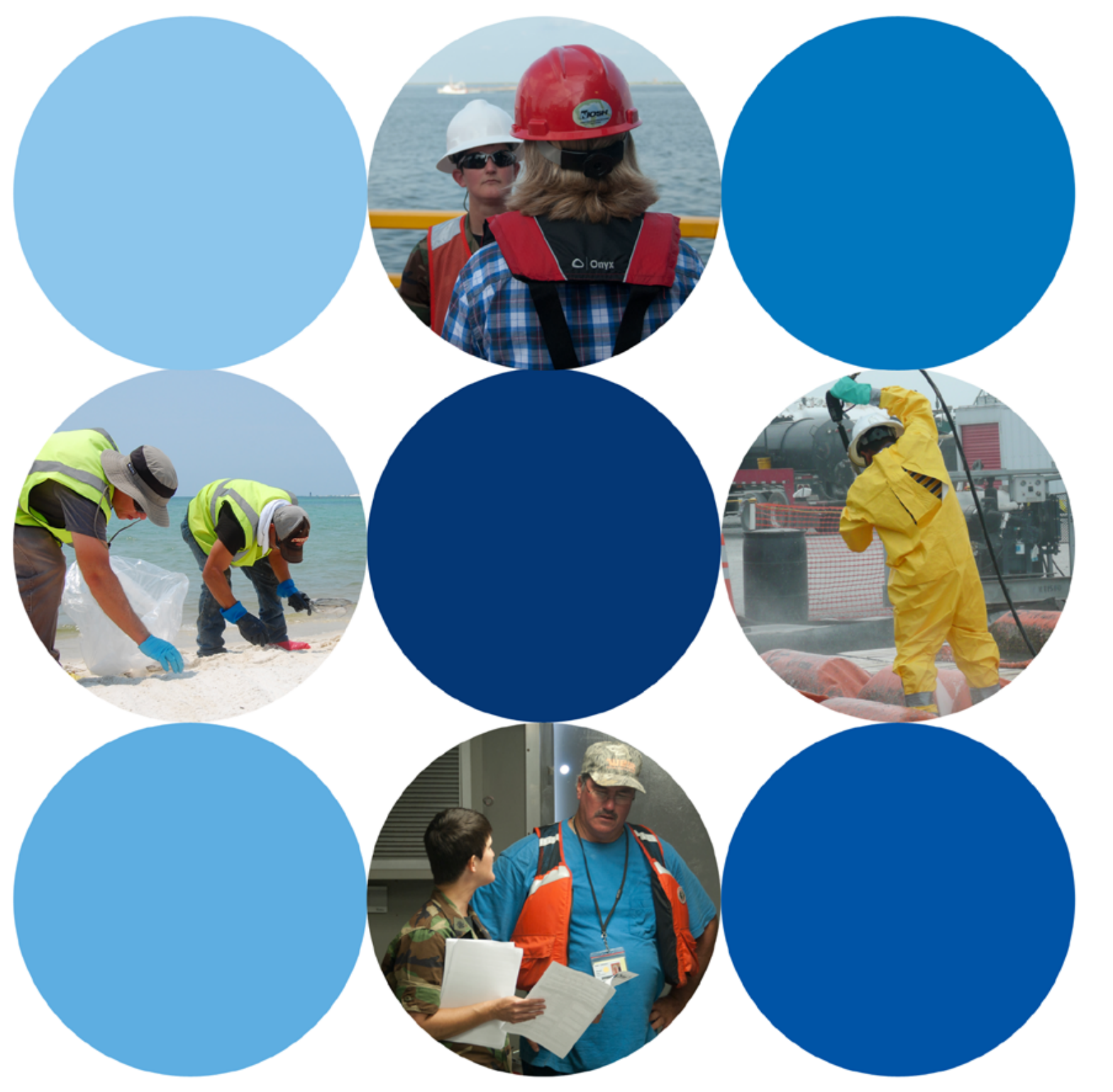





\section{Disclaimer}

Mention of any company or product does not constitute endorsement by the National Institute for Occupational Safety and Health (NIOSH). In addition, citations of Web sites external to NIOSH do not constitute NIOSH endorsement of the sponsoring organizations or their programs or products. Furthermore, NIOSH is not responsible for the content of these Web sites.

\section{Ordering Information}

To receive documents or other information about occupational safety and health topics, contact $\mathrm{NIOSH}$ at

Telephone: 1-800-CDC-INFO (1-800-232-4636)

TTY: 1-888-232-6348

E-mail: cdcinfo@cdc.gov

or visit the NIOSH Web site at www.cdc.gov/niosh.

For a monthly update on news at NIOSH, subscribe to NIOSH eNews by visiting www.cdc.gov/niosh/eNews.

DHHS (NIOSH) Publication No. 2011-175 


\section{Foreword}

The explosion on the Deepwater Horizon oil rig on April 20, 2010, resulted in the deaths of 11 workers and injuries to another 17 workers. In the weeks and months afterward, large amounts of crude oil were emitted from the Macondo Well. As a result, tens of thousands of workers engaged in onshore and offshore containment and cleanup activities. Concerns about the potential effects of the spill on human and environmental health in the Gulf, including potential risks to response workers, prompted an unprecedented response from agencies across the Federal, state, and local governments.

One of those responses involved experts from the National Institute for Occupational Safety and Health (NIOSH) "rostering" containment and cleanup workers. NIOSH developed this prospective roster with the following objectives: (1) to create a record of those who participated in the Deepwater Horizon Response activities, (2) to collect information on the nature of their projected work assignments and the training they received, and (3) to create a mechanism for contacting them about possible work-related symptoms of illness or injury during and after the response, as needed. To our knowledge, this is the first time that a prospective, centralized roster of workers has ever been developed for an event of this magnitude.

The NIOSH Deepwater Horizon Response rostering effort entailed the largest activation of NIOSH personnel to the field in the history of the Institute, involving close to 100 individuals. As a result, more than 55,000 workers were rostered. I am proud of everyone at NIOSH who participated in this unprecedented effort and want to express my appreciation for their hard work and dedication to the rostering effort.

The Deepwater Horizon Response presented unique challenges in pro $\neg$ tecting response workers spread across the Gulf region, who performed a wide range of activities in physically and emotionally demanding circumstances. The rostering was one of many important activities implemented to protect response workers. With publication of the NIOSH Deepwater Horizon Roster Summary Report, NIOSH shares with you the knowledge we gained about the Deepwater Horizon responder population, how to implement a rostering effort, and the future use of rosters in both man-made and natural disasters.

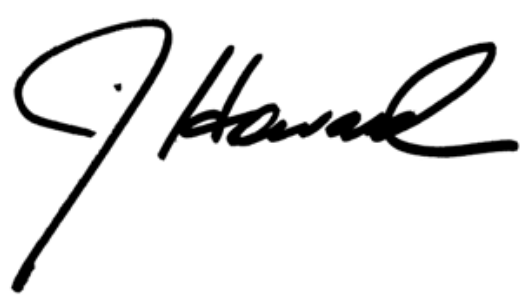

John Howard, M.D.

Director

National Institute for Occupational Safety and Health 


\section{Contents}

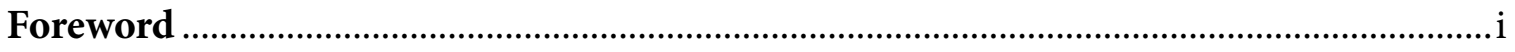

Abbreviations ................................................................................................................ iii

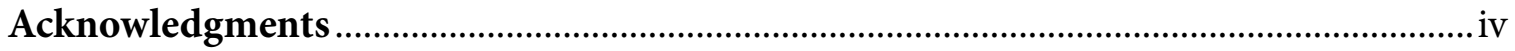

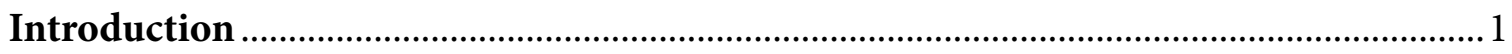

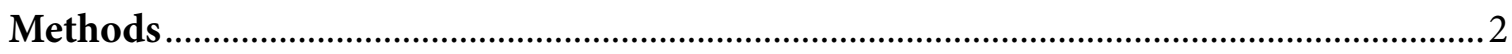

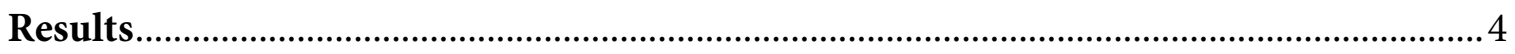

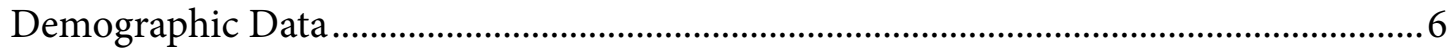

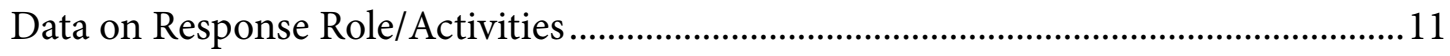

Data on Health Risk Factors .......................................................................................... 19

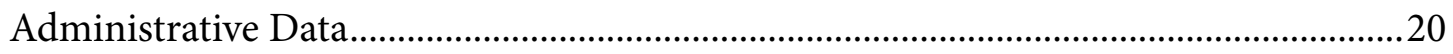

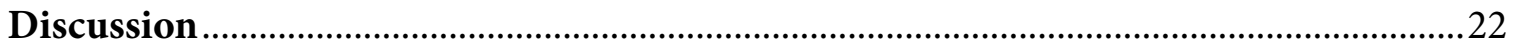

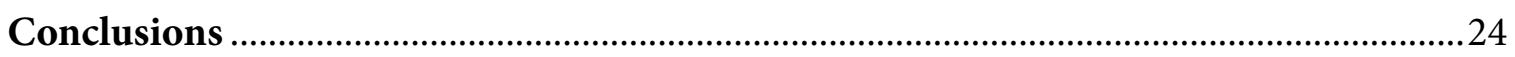

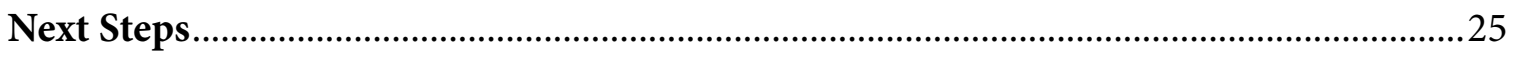

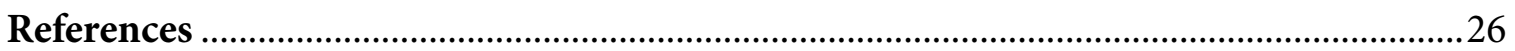

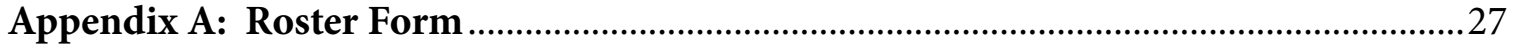

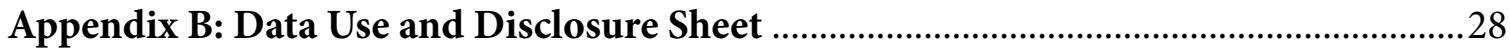




\section{Abbreviations}

CDC

DHHS

GuLF

HazMat

HAZWOPER

HSE

NAICS

NIEHS

$\mathrm{NIOSH}$

PPE

SOC

SSN
Centers for Disease Control and Prevention

Department of Health and Human Services

Gulf Long-term Follow-up Study

Hazardous materials

Hazardous Waste Operations and Emergency Response

Health, Safety, and Environment

North American Industrial Classification System

National Institute for Environmental Health Sciences

National Institute for Occupational Safety and Health

Personal protective equipment

Standard Occupational Classification

Social Security number 


\section{Acknowledgments}

The authors, Renée Funk, ${ }^{1}$ Matthew Groenewold, ${ }^{2}$ and Patricia Laber, ${ }^{2}$ gratefully acknowledge the hard work and contributions of the NIOSH Roster Team. This team consisted of approximately one hundred NIOSH staff members and contractors, who rostered workers at staging areas, coordinated efforts from the Houma and Mobile Command Centers, received and processed forms, and performed data entry, data cleaning, and data management.

The authors thank Rob Wolfe and Seleen Collins for their editorial support and contributions to the design and layout of this document.

Finally, we express special appreciation to the following individuals for serving as independent, external reviewers and providing comments that contributed to the development or improvement of this document:

Janie Gittleman, CPWR, The Center for Construction Research and Training

Michael Heumann, Oregon Health Authority

Michelle Lackovic, Louisiana Department of Health and Hospitals

Oleg Muravov, Agency for Toxic Substances and Disease Registry

Jennifer Ruseiki, U.S. Coast Guard

$1 \quad \mathrm{NIOSH}$, Emergency Preparedness and Response Office (Atlanta, GA)

$2 \mathrm{NIOSH}$, Division of Surveillance, Hazard Evaluations, and Field Studies (Cincinnati, OH) 


\section{INTRODUCTION}

On April 21, 2010, the Deepwater Horizon oil drilling rig in the Gulf of Mexico caught fire and sank, causing crude oil to gush from the well at the sea floor. The leaking well was capped on July 15, 2010, and on September 19, 2010, a relief well was completed. Thousands of workers ${ }^{3}$ responded to the onshore and offshore cleanup activities. The Unified Area Command reported over 45,000 workers at the height of the response [Unified Area Command 2010]. The National Institute for Occupational Safety and Health (NIOSH) was asked to support the Unified Area Command to establish a systematic roster of workers participating in response cleanup efforts.

The concept for the worker roster was developed by the Emergency Responder Health Monitoring and Surveillance Interagency Workgroup coordinated by NIOSH [NIOSH 2011]. This group drafted recommendations that roster information be collected prospectively rather than retrospectively, as occurred during the World Trade Center event in 2001, which proved to be difficult and time-consuming. NIOSH developed this prospective roster with the following objectives: (1) to create a record of those who participated in the Deepwater Horizon response cleanup activities, (2) to collect information on the nature of their projected work assignments and training received, and (3) to create a mechanism for contacting them about possible work-related symptoms of illness or injury, as needed. The Unified Area Command and BP supported the roster with the goal of identifying all workers involved in all response/cleanup activities.

To our knowledge, this was the first time that a prospective, centralized roster of workers had ever been developed for an event of this magnitude.

3 The term workers, as used throughout this report, refers to contractors, government and military personnel, volunteers, and BP employees. 


\section{METHODS}

Once the funding for this activity was secured from Unified Area Command, NIOSH staff developed a roster form (Appendix A), adapting elements from existing forms when possible, such as the Rapid Response Registry [ATSDR 2007] and CDC Natural Disaster Morbidity Surveillance forms [CDC 2008]. The Unified Area Command requested that the form be no more than one page. In addition to the roster form, a data use and disclosure sheet (Appendix B) was created, describing how the collected information would be used, how it would be kept private, and how to contact NIOSH staff leading this effort. Once the forms were completed, they were sent to the Office of Management and Budget for emergency Paperwork Reduction Act approval and translation into Spanish and Vietnamese. The roster was developed in these languages because the trainings where the roster would be administered were being taught in Spanish and Vietnamese. Rostering began on May 14, 2010.

Workers could be rostered in one of three ways. The first method was during safety training at official training sites (before or after being hired). Individuals conducting the safety training sessions were provided with information about the NIOSH rostering effort (which they would convey to trainees), along with copies of the roster form and disclosure document to distribute to trainees during the classes. The trainers collected the completed forms and mailed them back to NIOSH. Because training could be completed before a person was hired, an unknown proportion of persons who completed the roster never worked on the cleanup response. Approximately 40,000 workers were rostered by this mechanism.

Second, because rostering at training sites began after many workers had already been trained and assigned to a work location, NIOSH also deployed field teams to worksites and staging areas in the four affected states to attempt to roster workers at these locations. The rostering effort was the largest activation of NIOSH personnel in the history of the Institute, cumulatively deploying 62 staff into the field and involving close to 100 staff in total. Efforts were made to roster all workers regardless of whether they were working onshore or offshore, at command centers or staging areas, and regardless of their type of employment (employee, contractor, government employee, or volunteer). Given that rostering did not start until May, responders to the initial fire and sinking of the oil rig were likely missed. However, approximately 16,000 workers were rostered by this mechanism.

Third, NIOSH rostered oil spill response workers online through a NIOSH website that had provisions to secure personal data. NIOSH provided a website link to multiple federal agencies, health departments, and BP and asked them to refer workers to the website to complete the rostering form electronically. This mechanism was targeted toward rostering staff who worked out of command centers located in Houma, LA (for the state of Louisiana) and Mobile, AL (for Alabama, Mississippi, and Florida). Only 170 workers were rostered by this mechanism.

In all cases respondents were informed that participation in the roster was voluntary, that their information would be kept private to the extent allowed by law (Privacy Act: 5 U.S.C. 552a), and that the information collected would be maintained in a secure manner. The initial paper and online rostering forms each took workers approximately 5 minutes to complete. 
All completed roster forms were entered into a central database, recoded as necessary, and checked for errors. Responses to the question about usual occupation before the oil spill were coded according to the North American Industrial Classification System (NAICS) [U.S. Census Bureau 2011] and the Standard Occupational Classification (SOC) [BLS 2011].

More than 55,000 workers completed the roster form. Rostering ended January 31, 2011; however, the number of forms received each week had dropped off to low levels by mid-October. Workers had multiple opportunities to complete the roster and in some cases may have filled out the roster form more than once. It is estimated that approximately $6 \%$ of the roster forms are duplicates.

NIOSH established a policy that allows qualified external researchers to recruit individuals included in this roster for participation in future studies of possible persistent or long-term health effects [NIOSH 2010]. It has provided the roster database to the National Institute for Environmental Health Sciences (NIEHS) for contacting workers about participating in the Gulf Long-term Follow-up (GuLF) Study [NIEHS 2011]. 


\section{RESULTS}

\section{Demographics}

Rostered workers' states of residence largely were along the Gulf Coast: Louisiana (28\%), Alabama (24\%), Florida (22\%), Mississippi (17\%), and Texas (4\%) (Figure 1). Workers were predominantly male (81\%) (Figure 2), non-Hispanic white (51\%) or non-Hispanic black (36\%) (Figure 3), and speakers of English (97\%) (Figure 4). Most were in the following age ranges: 25-34 years (28\%), less than 25 years (24\%), 35-44 years (21\%), and 45-54 years (18\%) (Figure 5). The workers' usual occupations (when specified and codable according to the Standard Occupational Classification system) prior to the oil spill were, in descending frequency, as follows: construction and extraction (13\%); transportation and material moving (9\%); farming, fishing, and forestry (5\%); and management (4\%) (Table 1). Four percent were unemployed. On the basis of the North American Industrial Classification System, their usual industries prior to the oil spill were, in descending frequency, construction (16\%); transportation and warehousing (7\%); agriculture, forestry, fishing, and hunting (6\%); administrative and support (4\%); waste management and remediation services (4\%); and public administration (3\%) (Table 2). Workers had largely been employed in their usual occupations for more than one year (95\%) (Figure 6).

\section{Response Roles and Activities}

We asked workers what type of responder they were. The most frequently reported was contractor (56\%), followed by BP employee (9\%), volunteer (4\%), and government worker (2\%) (Figure 7). The majority of workers (88\%) said that they planned to work on the oil spill as long as work was available (Figure 8). Their anticipated job responsibilities during the oil spill, in descending frequency, were cleanup/manual labor (27\%), beach cleanup (8\%), boat and rigging operations (8\%), and administration and supervision (6\%) (Table 3). Sixty-six percent of workers responded that their job tasks would potentially involve exposure to oil or oily substances (Figure 9), and among those, their anticipated tasks that might result in oil exposure were general cleanup (14\%), beach cleanup (6\%), handling tar balls (5\%), boom operations (4\%), and decontamination (2\%) (Table 4). The highest level of event-sponsored response training completed was predominantly Module 3: Post-Emergency Spilled Oil Cleanup (44\%), followed by Module 2: Contractor Expectations (14\%) and Module 1: BP Health, Safety, and Environment (HSE) Basic Orientation (8\%) (Table 5). With regard to hazardous materials training, 32\% of workers had completed 40-hour Hazardous Waste Operations and Emergency Response (HAZWOPER) instruction, and 7\% had completed 24-hour HAZWOPER or Hazardous Materials (HazMat) Technician training (Table 6). Twenty-nine percent of workers were rostered at staging areas rather than training sites; Table 7 lists how many forms were collected at each staging area.

\section{Anticipated Use of Personal Protective Equipment}

Eighty-one percent of workers expected to use personal protective equipment (PPE) to protect their skin (Figure 10), and 85\% expected to use eye protection (Figure 11). Thirty-two percent of workers expected to use respiratory protection (Figure 12), and a similar percentage (28\%) had been fit-tested for a respirator within the past year (Figure 13). However, we were not able to determine whether the fit testing was for the respirator they would be using in this response. 


\section{Health Risk Factors}

Thirty-seven percent of workers reported that they smoke (Figure 14), and of those, the majority $(68 \%)$ reported smoking half a pack (10 cigarettes) or more per day (Figure 15). Most workers had received a tetanus vaccine within the past 10 years (71\%) (Figure 16).

\section{Administrative Data}

We report some administrative data for researchers interested in recruiting individuals from the roster for their own studies. The workers largely completed the contact information section, with the exception of e-mail address (47\% missing) (Table 8 ). The frequency of missing values for all other variables is reported on each figure and table throughout this document. The majority of responders were rostered through the training mechanism $(71 \%) ; 29 \%$ were rostered at staging areas by NIOSH staff, and only a small percentage $(<1 \%)$ used the online survey (Figure 17). Most workers $(80 \%)$ responded that they were willing to be contacted about participating in a possible post-event survey (Figure 18). 


\section{Demographic Data}

Figure 1. Distribution of Responders by State of Residence

\section{State of residence}

$$
(n=55,561)
$$

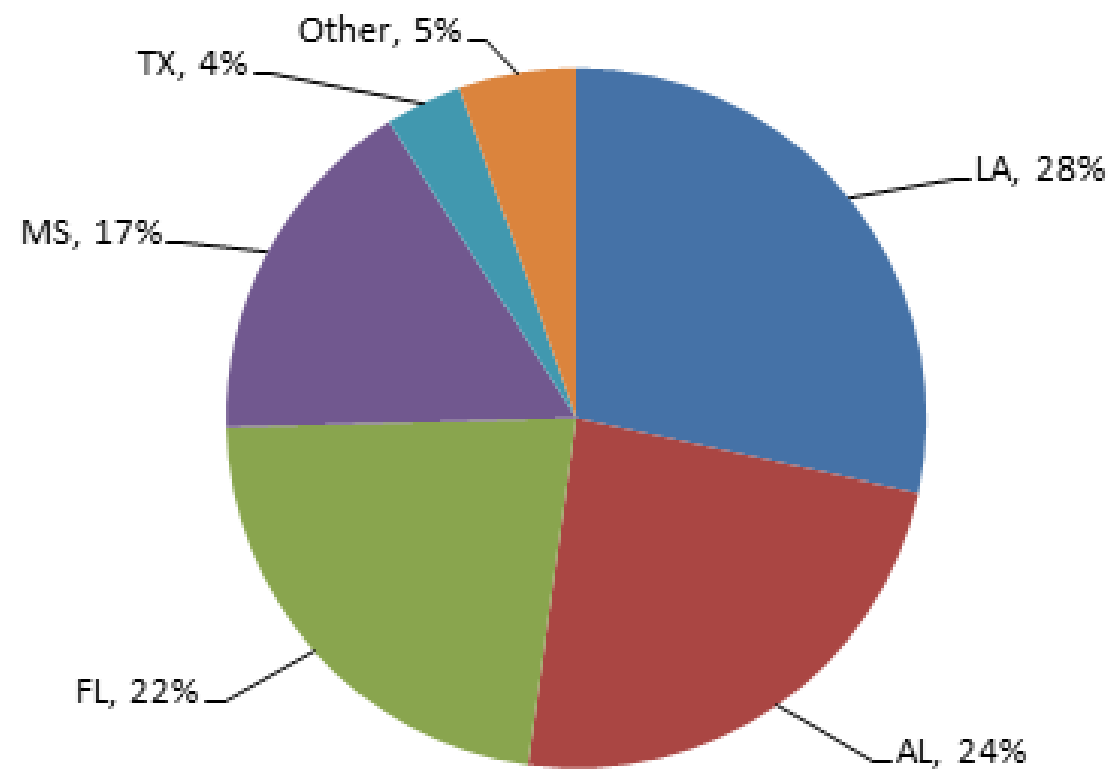


Figure 2. Distribution of Responders by Sex

$$
\begin{gathered}
\text { Sex } \\
(n=54,161)
\end{gathered}
$$

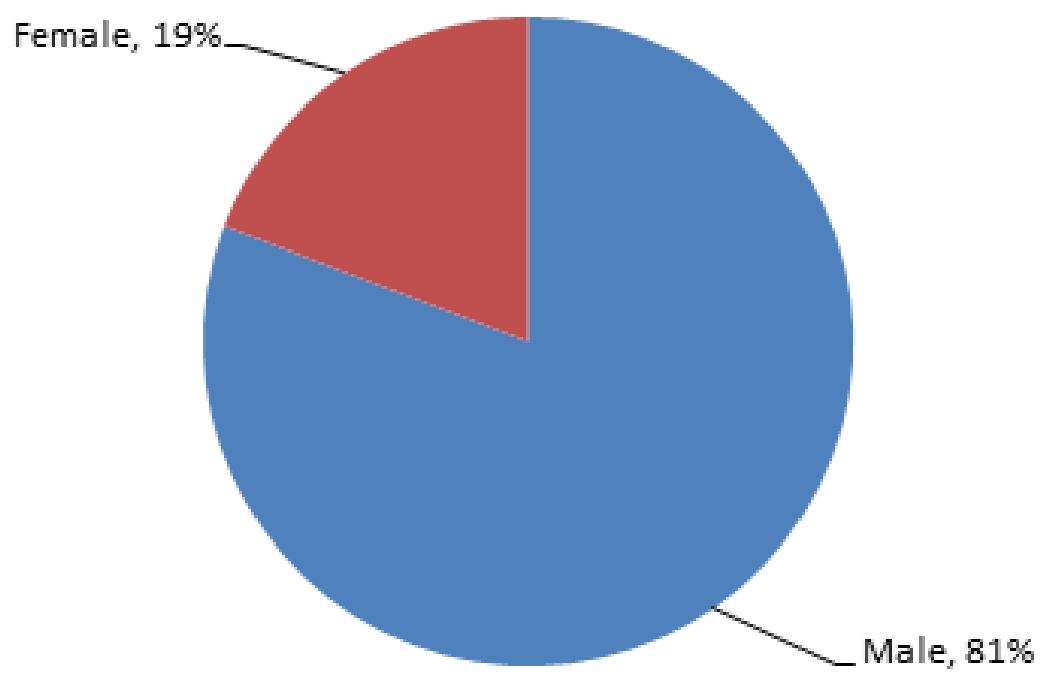

Figure 3. Distribution of Responders by Race/Ethnicity

\section{Race/ethnicity}

$$
(n=53,561)
$$

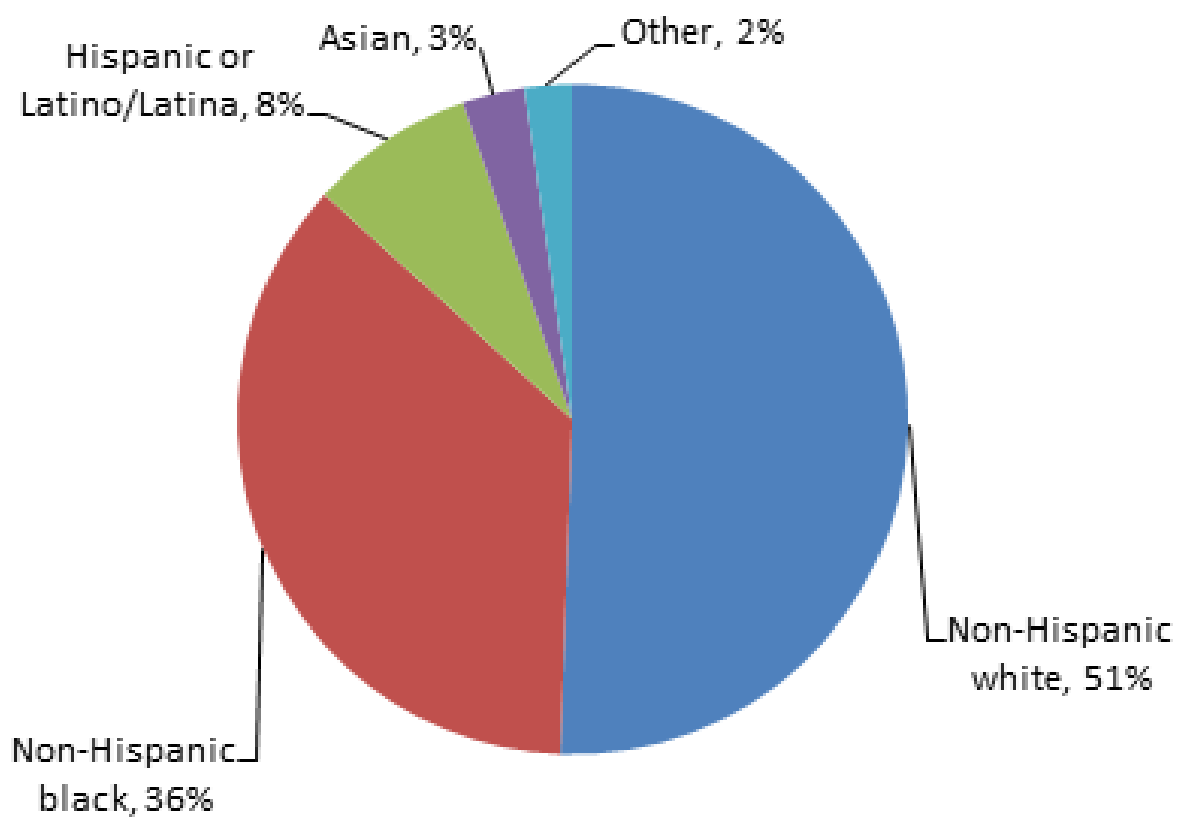


Figure 4. Distribution of Responders by Language of Form and/or Response

\section{Language of form and/or response}

$$
(n=55,282)
$$

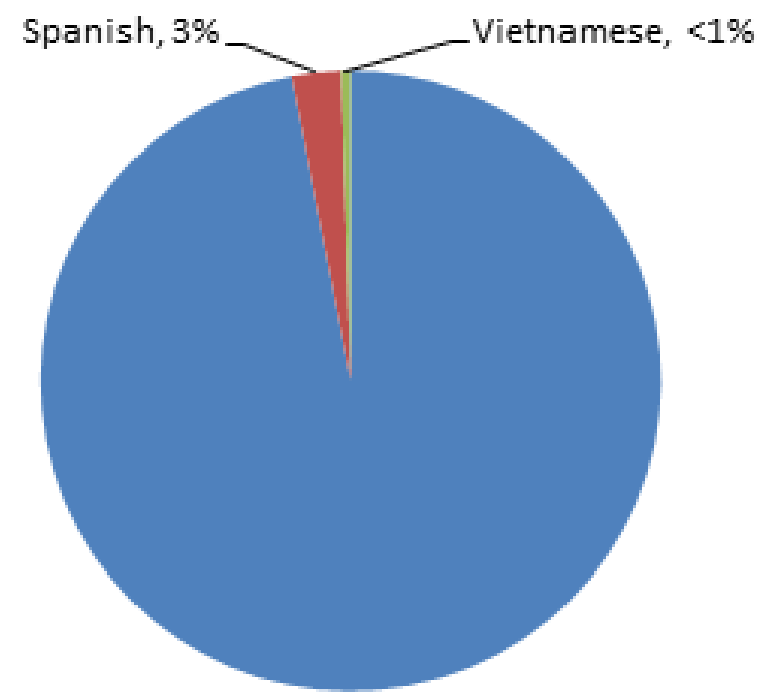

English, 97\%

Figure 5. Number and Distribution of Responders by Age Group ( $n=54,655)$

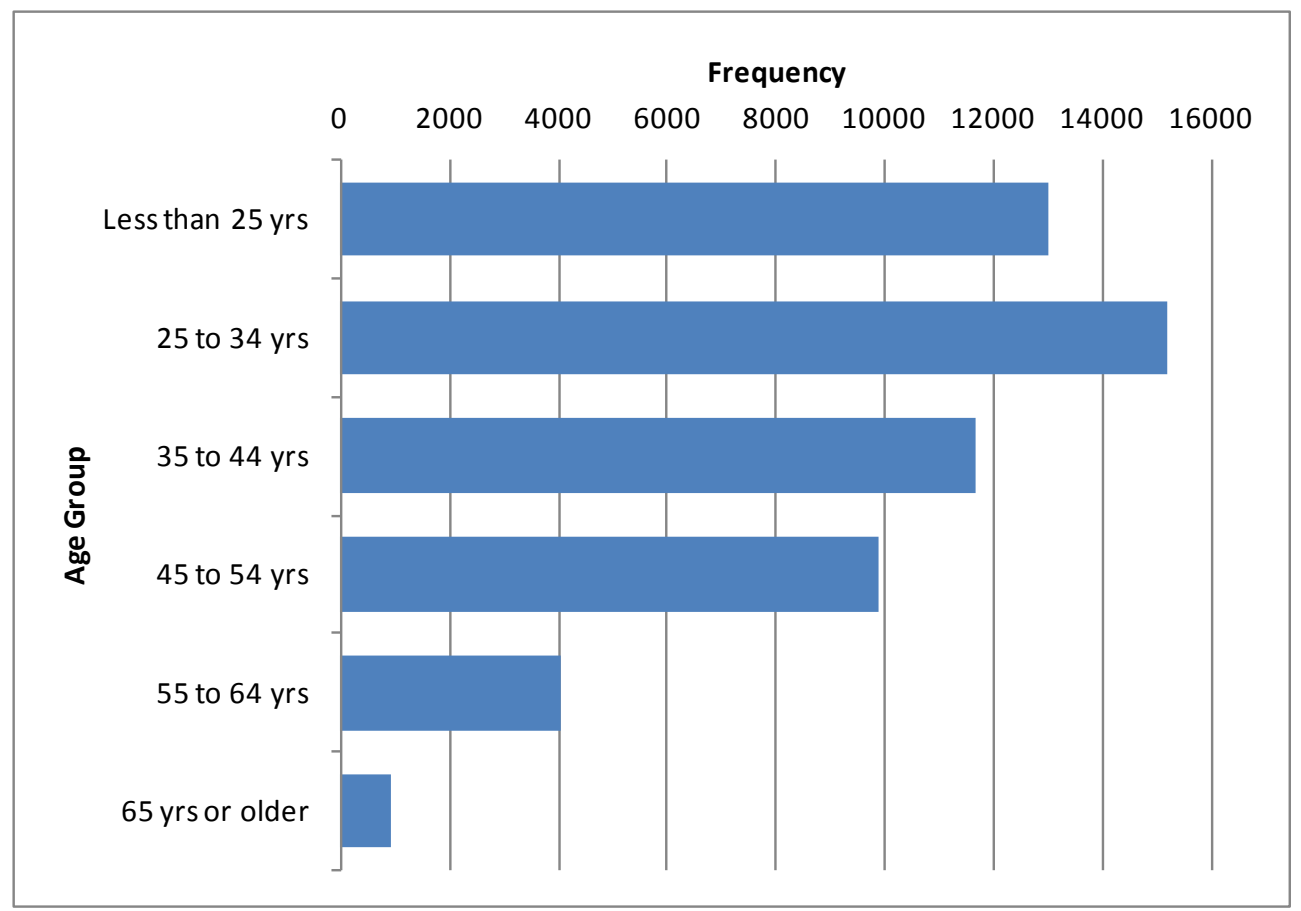

Pct. Cum. Pct

$23.79 \quad 23.79$

$27.76 \quad 51.55$

$21.34 \quad 72.90$

$18.08 \quad 90.98$

7.36 98.33

$1.67 \quad 100.00$ 
Table 1. Number and Distribution of Responders by Usual Occupation Prior to the Oil Spill ( $n=$ 46,512)

\begin{tabular}{rrr}
\hline Occupation (per SOC) & Frequency & Percent \\
\hline Construction and Extraction & 6258 & 13.45 \\
Transportation and Material Moving & 4135 & 8.89 \\
Farming, Fishing, and Forestry & 2536 & 5.45 \\
Unemployed (subset of Not Classifiable) & 2117 & 4.21 \\
Management & 1867 & 4.01 \\
Production & 1736 & 3.73 \\
Protective Service & 1381 & 2.97 \\
Food Preparation and Serving Related & 1322 & 2.84 \\
Installation, Maintenance, and Repair & 1219 & 2.62 \\
Building and Grounds Cleaning and Maintenance & 1075 & 2.31 \\
Sales and Related & 1032 & 2.22 \\
Office and Administrative Support & 955 & 2.05 \\
Arts, Design, Entertainment, Sports, and Media & 581 & 1.25 \\
Healthcare Practitioners and Technical & 534 & 1.15 \\
Life, Physical, and Social Science & 529 & 1.14 \\
Business and Financial Operations & 464 & 1.00 \\
Personal Care and Service & 458 & 0.98 \\
Architecture and Engineering & 390 & 0.84 \\
Education, Training, and Library & 311 & 0.67 \\
Healthcare Support & 295 & 0.63 \\
Computer and Mathematical & 136 & 0.29 \\
Community and Social Services & 65 & 0.14 \\
Lot Classifiable (except Unemployed, above) & 17054 & 37.01 \\
\hline Total & 46512 & 100.00 \\
\hline
\end{tabular}


Table 2. Number and Distribution of Responders by Usual Industry of Employment Prior to the Oil Spill $(n=46,512)$

\begin{tabular}{rrr}
\hline Industry (per NAICS) & Frequency & Percent \\
Construction & 7453 & 16.02 \\
Transportation and Warehousing & 3164 & 6.80 \\
Agriculture, Forestry, Fishing and Hunting & 2761 & 5.94 \\
Administrative and Support and Waste Management and Remediation Services & 2046 & 4.40 \\
Public Administration & 1521 & 3.27 \\
Retail Trade & 1418 & 3.05 \\
Manufacturing & 1330 & 2.86 \\
Professional, Scientific, and Technical Services & 1315 & 2.83 \\
Other Services (except Public Administration) & 1272 & 2.73 \\
Health Care and Social Assistance & 1188 & 2.55 \\
Arts, Entertainment, and Recreation & 728 & 1.57 \\
Educational Services & 471 & 1.01 \\
Mining, Quarrying, and Oil and Gas Extraction & 406 & 0.87 \\
Real Estate and Rental and Leasing & 400 & 0.86 \\
Finance and Insurance & 291 & 0.63 \\
Information & 121 & 0.26 \\
Utilities & 92 & 0.20 \\
Management of Companies and Enterprises & 8 & 0.02 \\
Not Classifiable & 20461 & 43.99 \\
\hline Total & 46512 & 100.00 \\
\hline
\end{tabular}


Figure 6. Number and Distribution of Responders by Tenure at Usual Occupation $(n=40,251)$

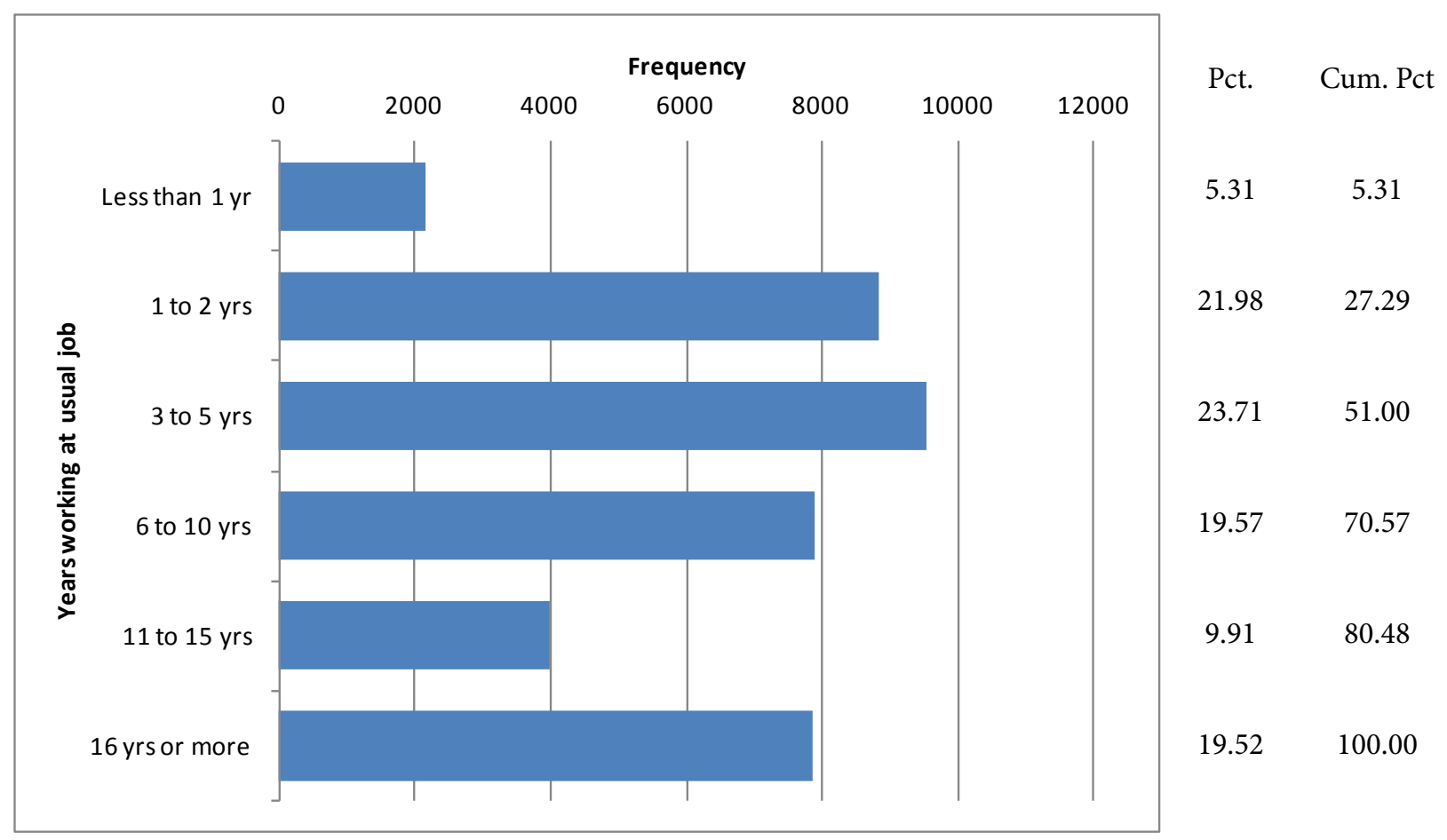

\section{Data on Response Role/Activities}

Figure 7. Number and Distribution of Workers by Responder Category

\section{Responder category}

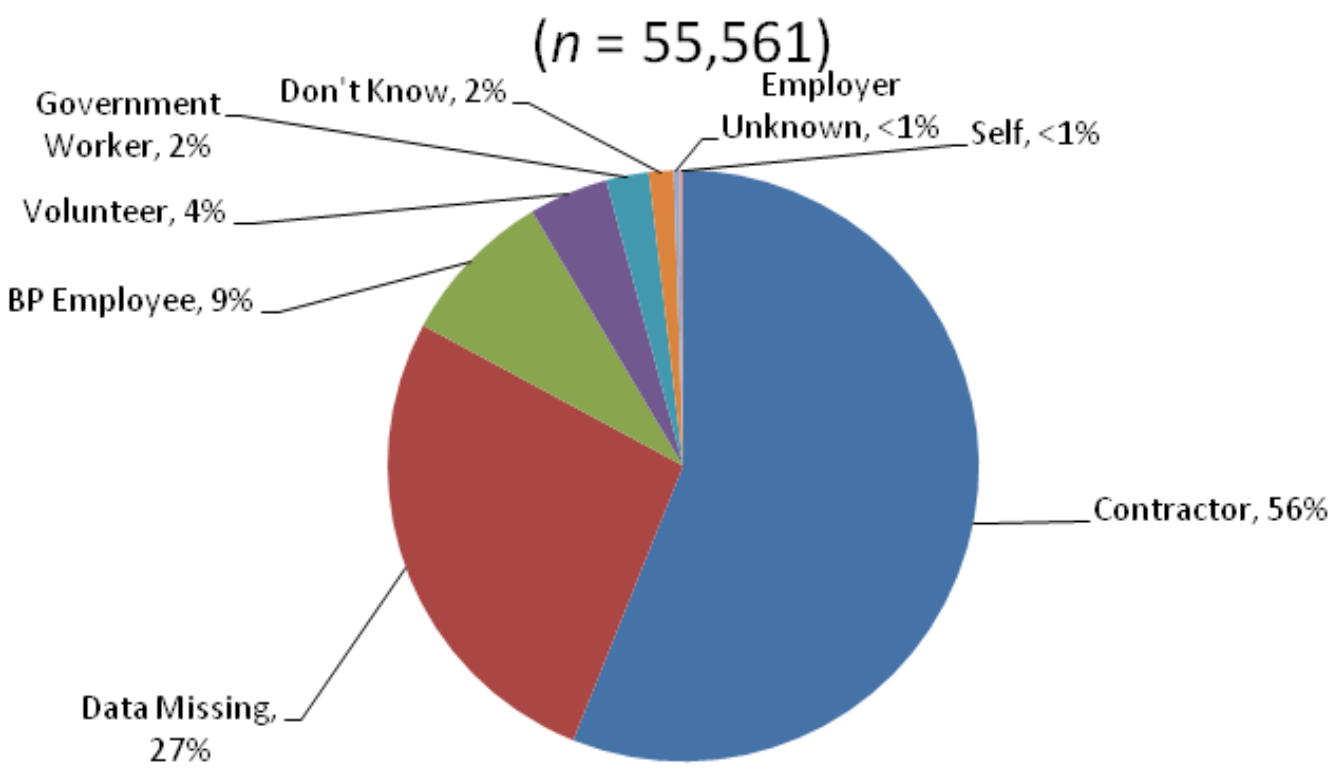


Figure 8. Number and Distribution of Responders by Planned Duration of Work $(n=51,870)$

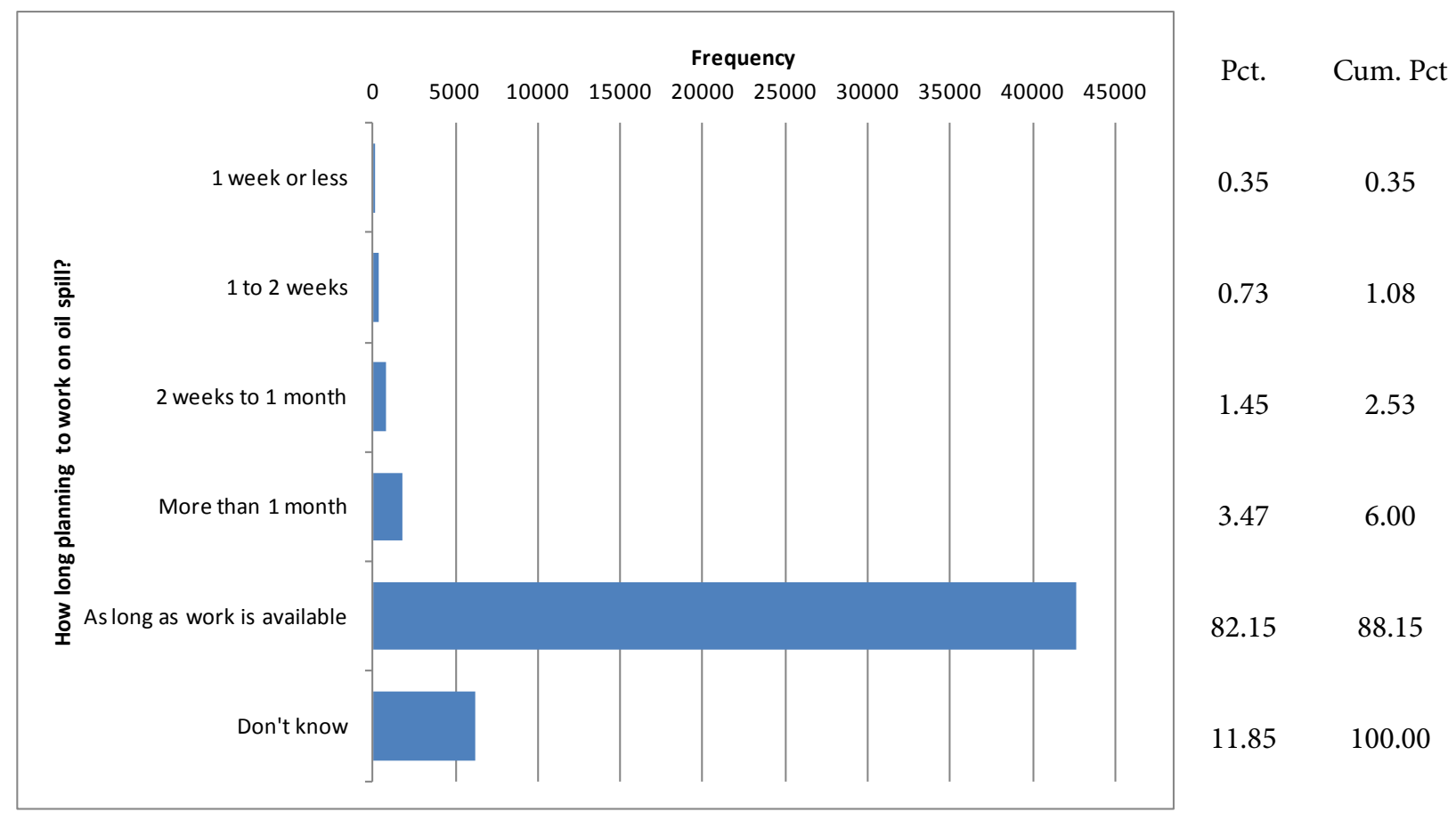

Table 3. Number and Distribution of Responders by Anticipated Job Responsibilities During the Oil Spill $(n=55,561)$

\begin{tabular}{lrr}
\hline Anticipated Job Responsibilities & Frequency & Percent \\
\hline General cleanup/labor & 15069 & 27.12 \\
General beach cleanup & 4393 & 7.91 \\
Boat and rigging operations & 4278 & 7.70 \\
Administration and supervision & 3366 & 6.06 \\
Safety and security & 2218 & 3.99 \\
Tar balls and weathered oil & 2021 & 3.64 \\
Skilled workers/equipment operations & 1429 & 2.57 \\
Boom operations & 1142 & 2.06 \\
Logistics and transportation & 1142 & 2.06 \\
Environmental and wildlife & 769 & 1.38 \\
Utility workers & 752 & 1.35 \\
Decontamination & 661 & 1.19 \\
Other responses & 652 & 1.17 \\
Waste management & 425 & 0.76 \\
Oil sighting & 416 & 0.75 \\
General water cleanup & 413 & 0.74 \\
Oil skimming & 278 & 0.50 \\
No response/do not know & 15866 & 28.56 \\
\hline Total & 55,561 & 100.00 \\
\hline
\end{tabular}


Figure 9. Distribution of Responders by Anticipated Exposure to Oil

\section{Will your tasks involve exposure tooil?}

$$
(n=49,940)
$$

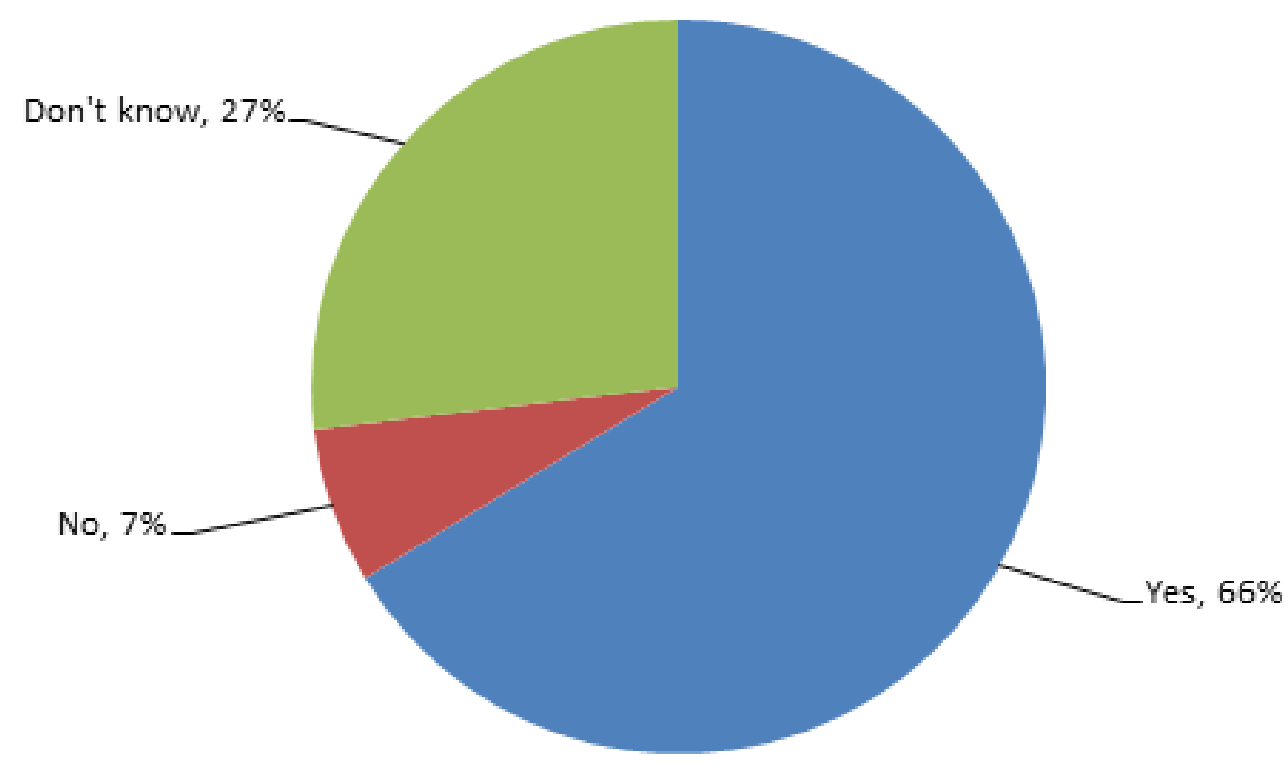


Table 4. Number and Distribution of Responders by Anticipated Source of Exposure to Oil ( $n=$ $55,561)$

\begin{tabular}{lrr}
\hline Anticipated Source of Exposure & Frequency & Percent \\
\hline General cleanup & 7599 & 13.68 \\
General beach cleanup & 3193 & 5.75 \\
Tar balls & 3045 & 5.48 \\
Boom operations & 2422 & 4.36 \\
Decontamination & 1345 & 2.42 \\
Shoveling and bagging & 841 & 1.51 \\
Other responses & 822 & 1.48 \\
Weathered oil & 774 & 1.39 \\
Boat crews & 751 & 1.35 \\
Administration \& oversight & 639 & 1.15 \\
Equipment operations & 503 & 0.91 \\
Skimming operations & 485 & 0.87 \\
General water cleanup & 384 & 0.69 \\
Debris pickup & 337 & 0.61 \\
Animal \& wildlife & 322 & 0.58 \\
Safety \& security personnel & 302 & 0.54 \\
Oil vacuuming & 219 & 0.39 \\
Oil sighting & 177 & 0.32 \\
Laboratory testing & 133 & 0.24 \\
Waste disposal & 102 & 0.18 \\
\hline Unknown & 31166 & 56.09 \\
\hline Total & 55561 & 100.00 \\
\hline
\end{tabular}


Table 5. Number and Distribution of Responders by Highest Level of Event-Sponsored Response Training Completed $(n=55,561)$

\begin{tabular}{rrrrr}
\hline & & & Cumulative & Cumulative \\
Highest Level of Event Training Completed & Frequency & Percent & Frequency & Percent \\
\hline None & 19075 & 34.33 & 19075 & 34.33 \\
Module 1: BP HSE Basic Orientation & 4307 & 7.75 & 23382 & 42.08 \\
Module 2: Contractor Expectations & 7744 & 13.94 & 31126 & 56.02 \\
Module 3: Post-Emergency Spilled Oil Cleanup & 24435 & 43.98 & 55561 & 100.00 \\
\hline
\end{tabular}

Table 6. Number and Distribution of Responders by Highest Level of Hazardous Materials Training Completed $(n=55,561)$

\begin{tabular}{rrrrr}
\hline Highest Level of Hazardous Materials Train- & & & Cumulative & Cumulative \\
ing Completed & Frequency & Percent & Frequency & Percent \\
\hline None & 32242 & 58.03 & 32242 & 58.03 \\
First Responder Awareness & 835 & 1.50 & 33077 & 59.53 \\
8-Hour First Responder Operations & 811 & 1.46 & 33888 & 60.99 \\
24-Hour HAZWOPER or HazMat Technician & 3857 & 6.94 & 37745 & 67.93 \\
40-Hour HAZWOPER & 17816 & 32.07 & 55561 & 100.00 \\
\hline
\end{tabular}


Table 7. Number and Distribution of Responders by Deployment Location at Time of Data Collection*

\begin{tabular}{|c|c|c|}
\hline $\begin{array}{l}\text { Location of Form } \\
\text { Collection }\end{array}$ & Frequency & Percent \\
\hline Abbeville, LA & 210 & 1.31 \\
\hline Apalachicola, FL & 123 & 0.77 \\
\hline Bay St. Louis, MS & 112 & 0.70 \\
\hline Bayou Caddy, MS & 280 & 1.75 \\
\hline Bayou Chico, FL & 157 & 0.98 \\
\hline Bayou La Batre, AL & 101 & 0.63 \\
\hline Berwick, LA & 69 & 0.43 \\
\hline Biloxi, MS & 336 & 2.10 \\
\hline Carabelle, FL & 69 & 0.43 \\
\hline Chauvin, LA & 55 & 0.34 \\
\hline Cocodrie, LA & 272 & 1.70 \\
\hline Dauphin Island, AL & 398 & 2.49 \\
\hline Destin, FL & 378 & 2.36 \\
\hline Dulac, LA & 251 & 1.57 \\
\hline Elmers Island, LA & 15 & 0.09 \\
\hline Fairhope, AL & 72 & 0.45 \\
\hline Fort Jackson, LA & 42 & 0.26 \\
\hline Fort Morgan, AL & 39 & 0.24 \\
\hline Fort Pickens, FL & 19 & 0.12 \\
\hline Fourchon Station, LA & 10 & 0.06 \\
\hline Fourchon, LA & 246 & 1.54 \\
\hline Freeport, FL & 56 & 0.35 \\
\hline Golden Meadow, LA & 199 & 1.24 \\
\hline Grand Isle \& Dulac, LA & 11 & 0.07 \\
\hline Grand Isle Beach, LA & 131 & 0.82 \\
\hline Grand Isle, LA & 1440 & 9.01 \\
\hline Grayton Beach, FL & 14 & 0.09 \\
\hline Gulf Shores, AL & 699 & 4.37 \\
\hline Gulf State Park, AL & 22 & 0.14 \\
\hline Gulfport, MS & 1341 & 8.39 \\
\hline Hammond, LA & 20 & 0.13 \\
\hline Homeport, LA & 30 & 0.19 \\
\hline
\end{tabular}

\begin{tabular}{lrr}
\hline Location of Form & & \\
Collection & Frequency & Percent \\
\hline Hopedale, LA & 263 & 1.65 \\
Houma, LA & 305 & 1.91 \\
Intracoastal City, LA & 47 & 0.29 \\
Lafitte, LA & 135 & 0.84 \\
Miramar Beach, FL & 89 & 0.56 \\
Mobile, AL & 30 & 0.19 \\
Myrtle Grove, LA & 101 & 0.63 \\
Orange Beach, AL & 1136 & 7.11 \\
Panama City Beach, FL & 86 & 0.54 \\
Panama City, FL & 656 & 4.10 \\
Pascagoula, MS & 1643 & 10.28 \\
Pass Christian, MS & 169 & 1.06 \\
Pensacola Beach, FL & 496 & 3.10 \\
Pensacola, FL & 562 & 3.52 \\
Point-Aux-Chenes, LA & 27 & 0.17 \\
Port St Joe, FL & 795 & 4.97 \\
Port-Aux-Chenes, LA & 14 & 0.09 \\
Robert, LA & 2 & 0.01 \\
Schiever, LA & 74 & 0.46 \\
Shell Beach, LA & 99 & 0.62 \\
Slidell, LA & 208 & 1.30 \\
St Andrews Marina, FL & 68 & 0.43 \\
St Mary, LA & 158 & 0.99 \\
Tallahassee, FL & 31 & 0.19 \\
Theodore, AL & 569 & 3.56 \\
Venice, FL & 159 & 0.99 \\
Venice, LA & 746 & 4.67 \\
Weeks Bay, AL & 13 & 0.08 \\
\hline Unknown & 99 & 0.57 \\
\hline Total & & \\
\hline & & 100.00 \\
\hline
\end{tabular}

${ }^{\star}$ Note: The universe for this analysis is responders from whom data were collected in the field $(n=15,997)$. It does not include responders whose data collection forms were sent in from training locations $(n=39,564)$. 
Figure 10. Number and Distribution of Responders by Anticipated Use of PPE for Skin Expecting to use PPE for skin

$$
(n=52,071)
$$

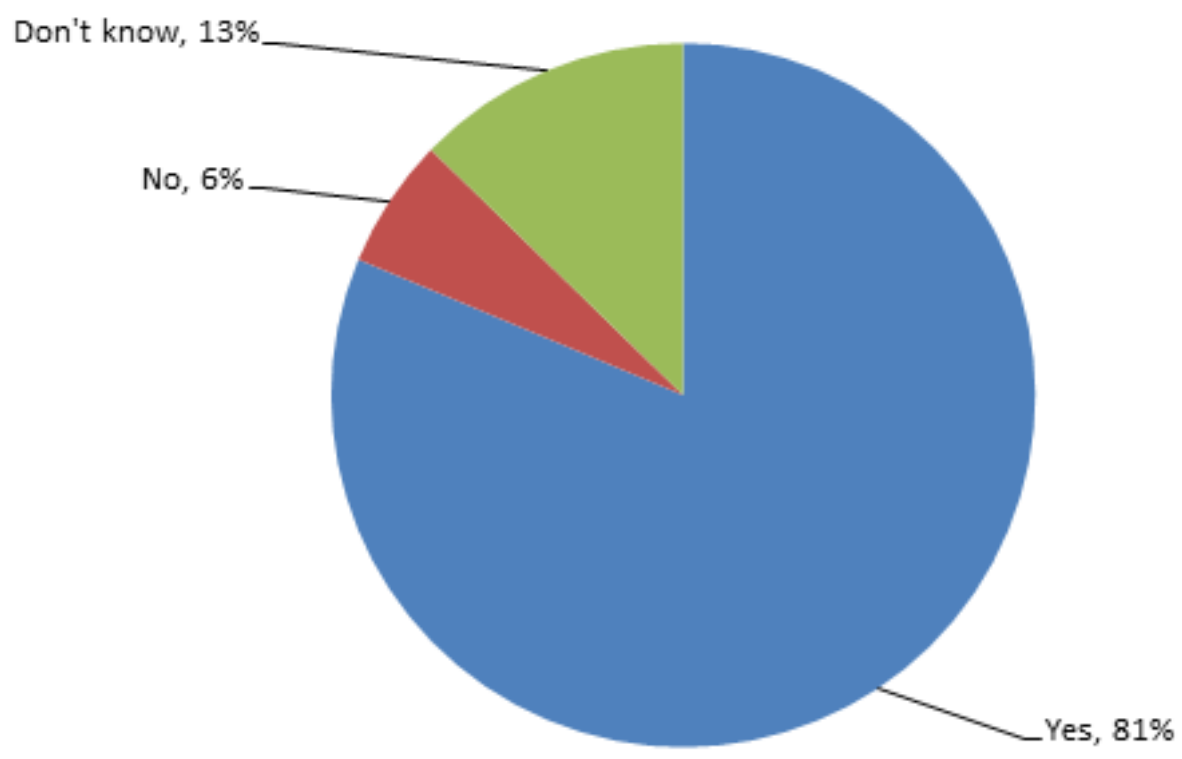

Figure 11. Distribution of Responders by Anticipated Use of PPE for Eyes

\section{Expecting to use PPE for eyes}

$$
(n=51,700)
$$

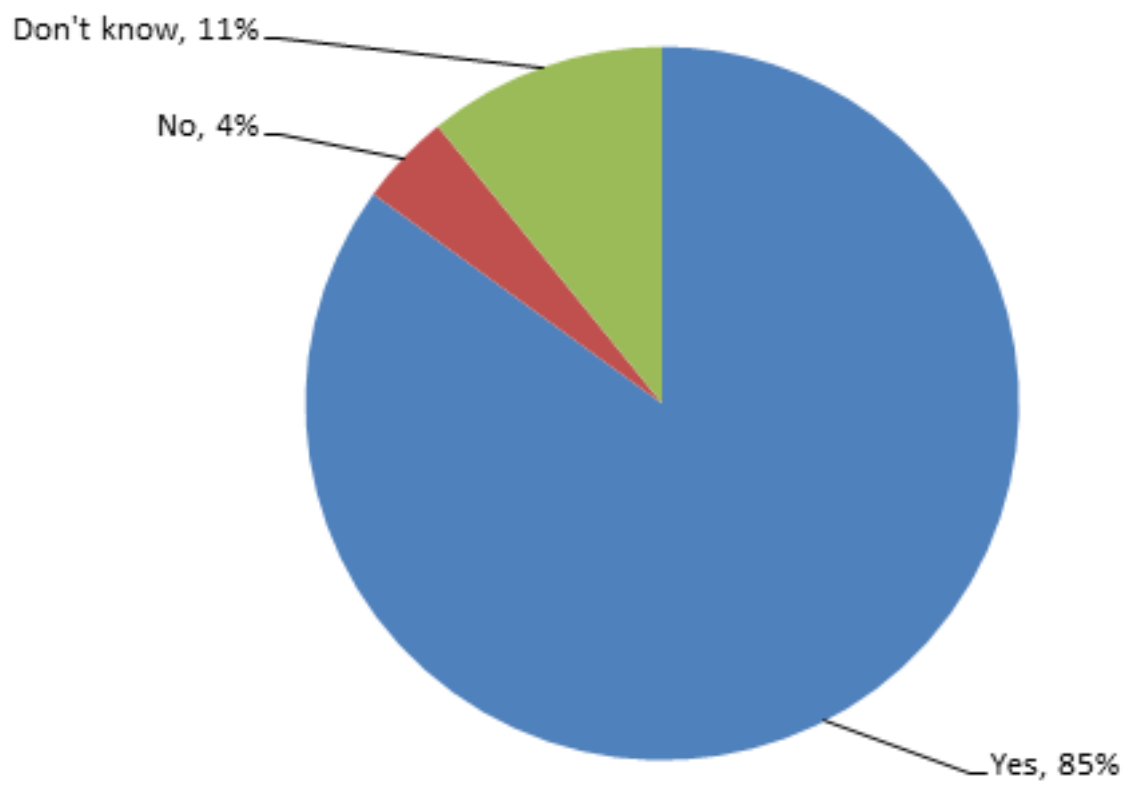


Figure 12. Distribution of Responders by Anticipated Use of Respiratory Protection

\section{Expecting to use respiratory protection}

$$
(n=51,702)
$$

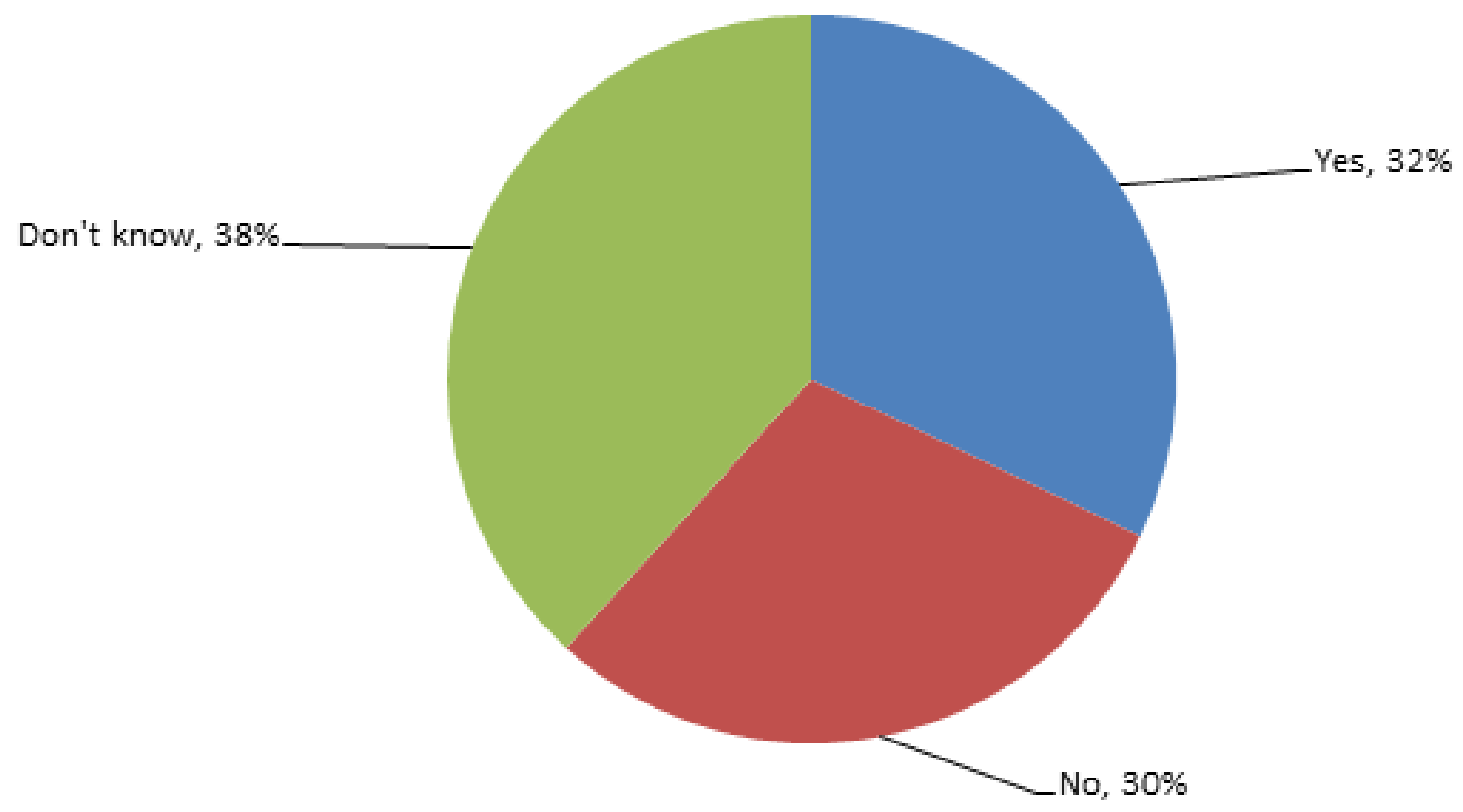

Figure 13. Distribution of Responders by Respirator Fit-Test Status

\section{Have you been fit-tested in the past year?}

$$
(n=50,856)
$$

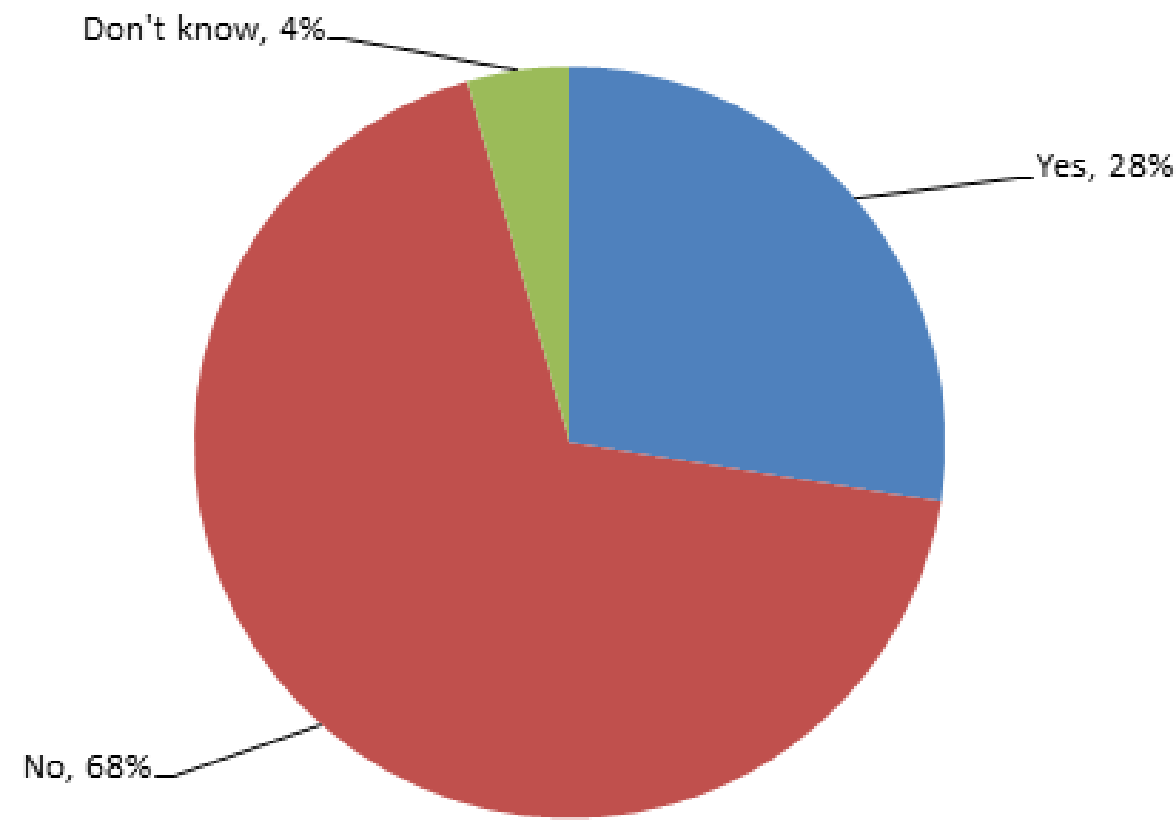




\section{Data on Health Risk Factors}

Figure 14. Distribution of Responders by Smoking Status

\section{Do you smoke?$$
(n=52,248)
$$

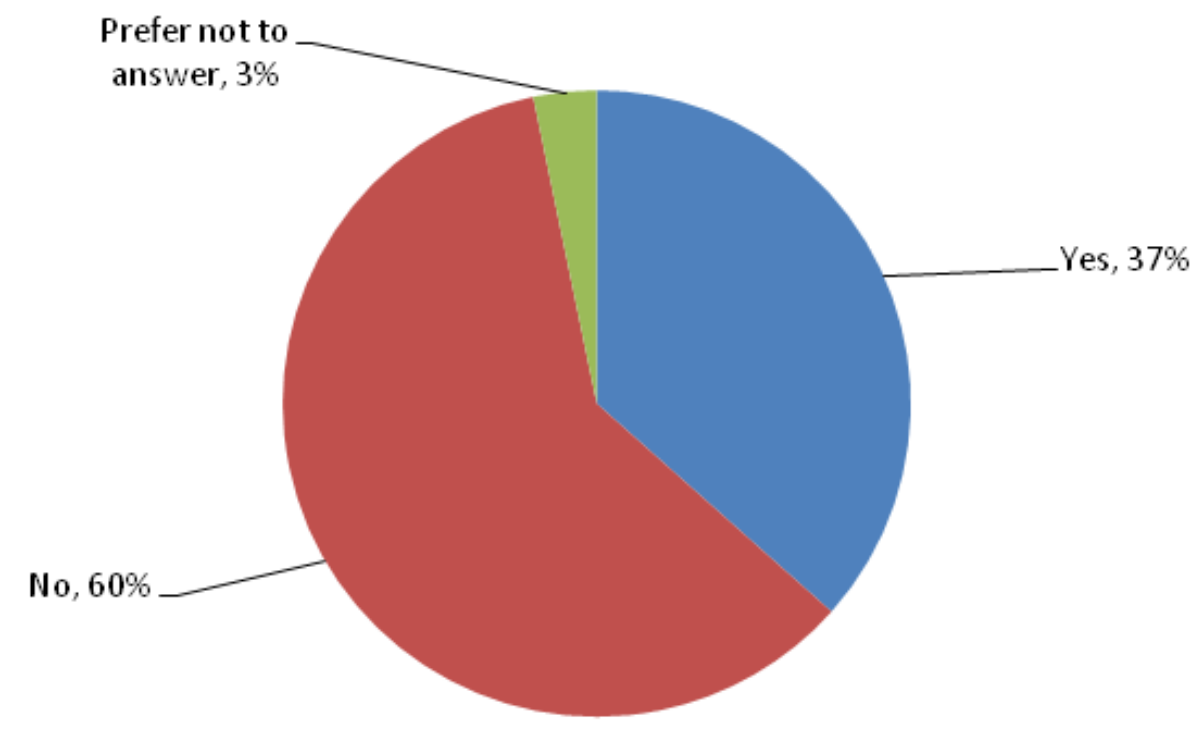

Figure 15. Number and Distribution of Responders Who Reported Being Smokers, by Number of Cigarettes Smoked Per Day $(n=17,377)$

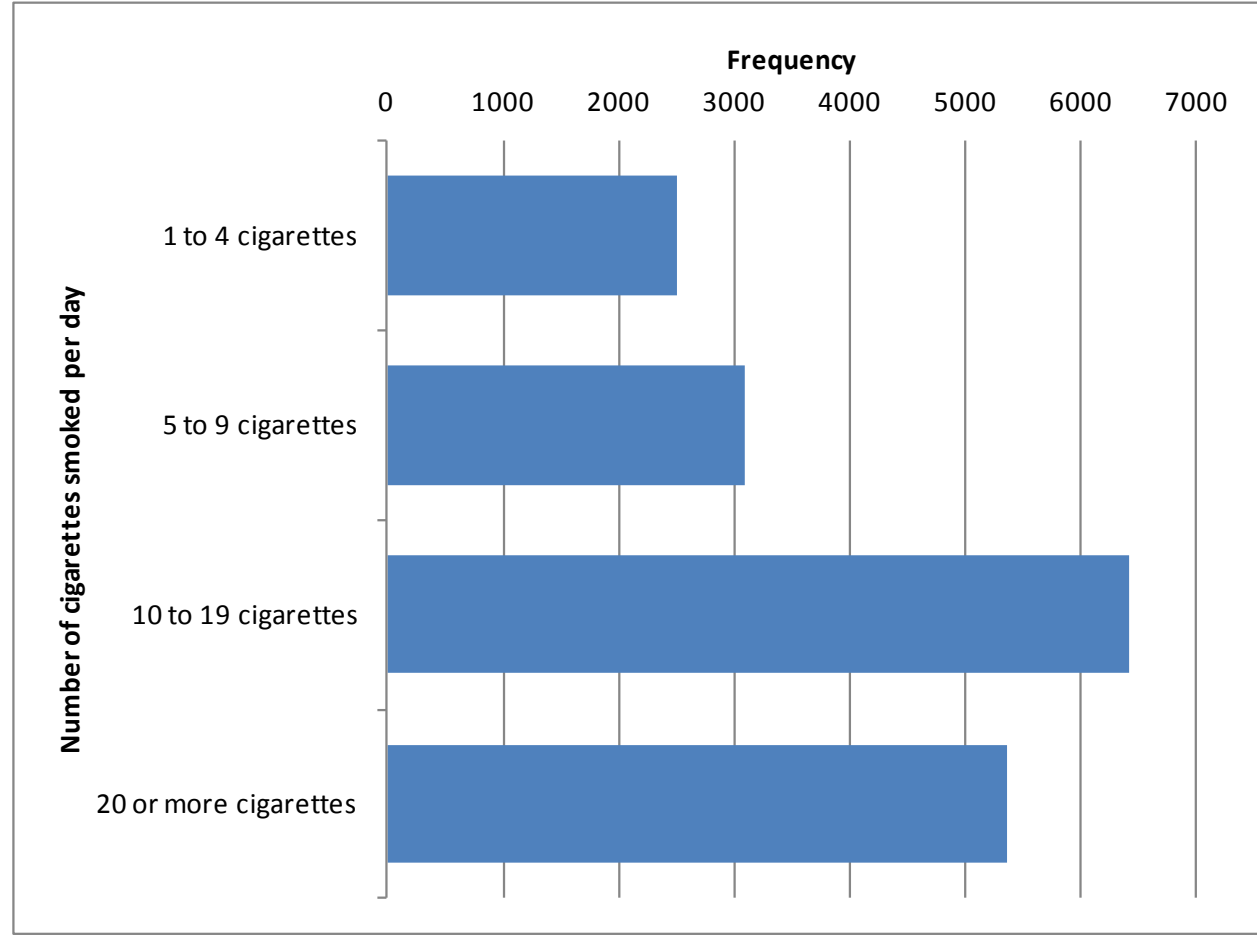

Pct. Cum. Pct

14.39

14.39

17.83

32.23

36.92

69.14

30.86

100.00 
Figure 16. Distribution of Responders by Tetanus Vaccination Status

\section{Tetanus vaccination within past 10 years}

$$
(n=50,855)
$$

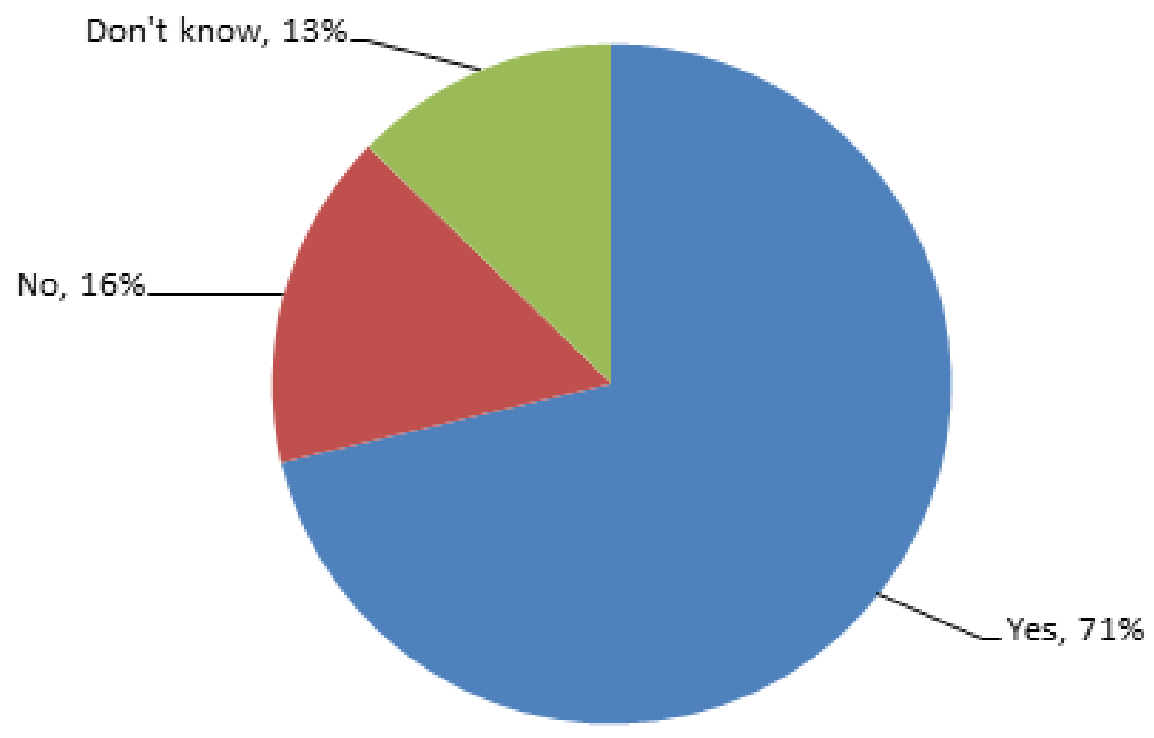

\section{Administrative Data}

Table 8. Frequency and Percentage of Missing Observations for Selected Roster Database Variables

\begin{tabular}{rrr}
\hline Variable & $\begin{array}{r}\text { Frequency } \\
\text { Missing }\end{array}$ & $\begin{array}{r}\text { Percent } \\
\text { Missing }\end{array}$ \\
\hline Last name & 94 & 0.17 \\
First name & 461 & 0.83 \\
Date of birth & 906 & 1.63 \\
SSN, last four digits & 922 & 1.66 \\
Street address & 458 & 0.82 \\
City & 401 & 0.72 \\
State & 360 & 0.65 \\
Zip code & 594 & 1.07 \\
Cell phone number & 3121 & 5.62 \\
E-mail & 26278 & 47.30 \\
Contact last name & 5643 & 10.16 \\
Contact phone number & 6064 & 10.91 \\
\hline
\end{tabular}


Figure 17. Distribution of Form Receipt, by Survey Method

\section{Form receipt, by survey method}

$$
(n=55,561)
$$

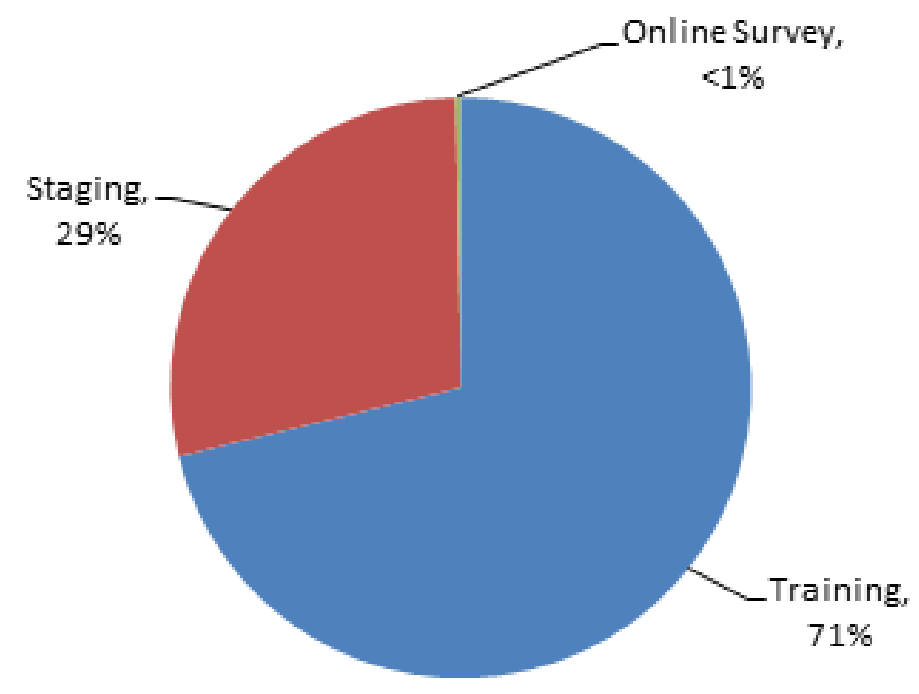

Figure 18. Frequency and Distribution of Responders by Willingness to Participate in Follow-up Survey

\section{Willing to participate in post-event survey}

$$
(n=45,778)
$$

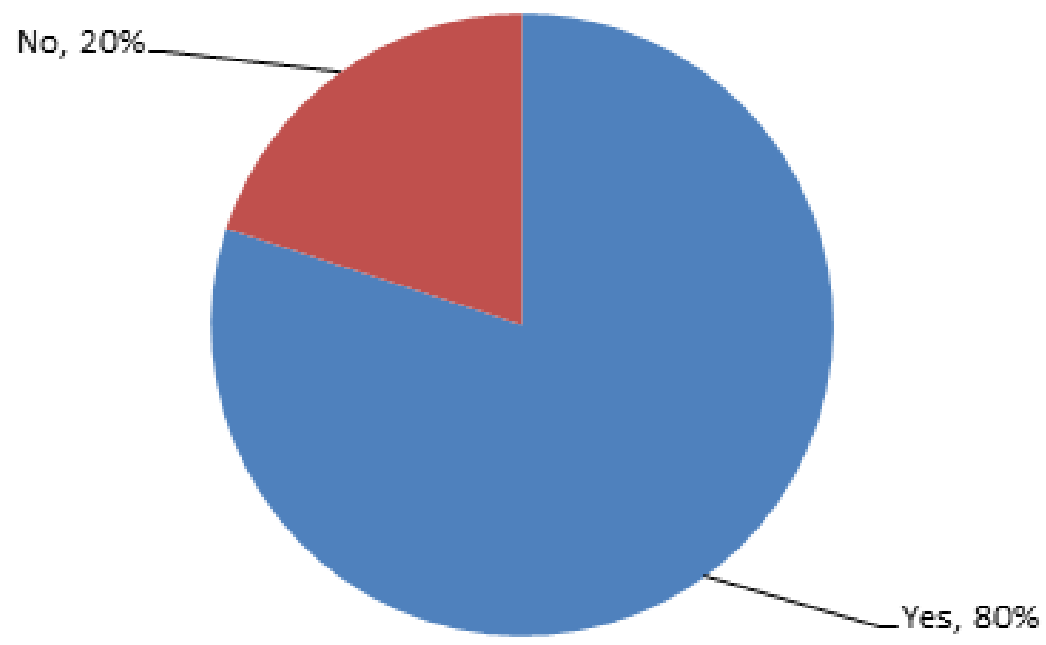




\section{DISCUSSION}

Analysis of the roster data presented above reveals that the Deepwater Horizon workforce had many similarities, such as being primarily from Gulf Coast states, male, English-speaking, and contractors. They were also diverse in many ways, including their usual occupation, age range, race/ethnicity, and anticipated job responsibilities during the Deepwater Horizon event.

One interesting finding was the high rate of smoking (37\%) in this workforce, compared with that in the general U.S. population (17.9\%) [CDC 2009]. Given the demographics of this group, the somewhat higher rate would be expected; however, the rate in this workforce is more than twice the national average. Researchers will need to be mindful of this finding when assessing respiratory symptoms in this workforce.

Notably, approximately one-third reported no event-sponsored response training. There are several possible reasons for this. (1) Because the question asked about completed training and many filled out the form on their first training day, they may have been compelled to mark "none." (2) Event-sponsored training was not required for command center workers until later in the event, which may have been after they were rostered. (3) This finding persists when the data are restricted to those rostered at staging areas, presumably after training was completed, suggesting that pockets of workers were not trained before beginning their tasks. We are aware of instances in which such workers were identified and sent back for training, but they may have already completed roster forms.

Regarding hazardous materials training, 32\% reported having completed the 40-hour HAZWOPER course. A similar percentage (32\%) reported expecting to use respiratory protection, and a slightly smaller percentage (28\%) reported having been fit-tested for a respirator within the past year. Further analysis reveals that approximately half of those who expected to use respiratory protection had completed 40-hour HAZWOPER training. This suggests that those with prior respirator training have an expectation of wearing respiratory protection, whereas those without such training do not.

Completion of all questions on the roster, especially of the free-text fields, was not optimal; consequently, the roster's utility as an analytic dataset is limited. With the exception of e-mail addresses, however, completion of contact information was quite good. This observation, plus the finding that the majority of rostered workers indicated willingness to be contacted about participating in a follow-up survey, suggests that the roster may be useful as a sampling frame for future follow-up studies.

Free-text fields, such as for questions about expected PPE use, job responsibilities, and exposure sources, were often left blank, and the responses that were given were difficult to analyze and interpret. Participants might have skipped these questions because they perceived them as difficult or time-consuming. Also, because many workers completed the roster during training, the low response rate for these questions may indicate that the workers knew little about what they would be doing before they started working. The question about expected job responsibilities was meant to elicit the response occupation or job title, but generally workers did not interpret it that way. In the future, we will ask directly about response occupation so that we can code answers by using standard industry and occupation coding schemes [BLS 2011]. The one-page limit led to inclusion

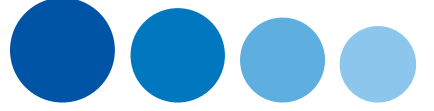


of more free-text fields than desirable, but for future events we will replace these with precoded answers whenever possible.

Few health questions were included on the roster form. We intended to conduct a health survey of the rostered workers later and therefore asked only about health issues that were actionable during the event: smoking and tetanus vaccination status. Smoking status data aided interpretation of respiratory symptoms collected through injury and illness reporting during the event. Tetanus vaccination status was used to inform vaccine supply needs. On future roster forms, we intend to use the health questions identified in the predeployment health screening section of the Emergency Responder Health Monitoring and Surveillance document [NIOSH 2011]. 


\section{CONCLUSIONS}

Rostering of response workers is an essential tool for real-time health surveillance, depending on the length of the response, and for potential long-term follow-up of health status. NIOSH and other response organizations realized the value of rostering as a lesson learned from the World Trade Center emergency response. The rostering project was intended to be completed during mandatory worker training. However, many cleanup workers had already completed training before rostering was incorporated into the training protocol. This necessitated a labor-intensive effort by NIOSH staff to deploy across the Gulf Coast staging areas to conduct rostering. The following observations on rostering can be drawn from the Deepwater Horizon response event:

- Begin rostering immediately and integrate it into response activities as soon as possible, to ensure that all workers are included. Consider state and local public health departments as possible resources for this activity.

- Have a ready-to-use roster form that can be quickly adapted and cleared for use.

- Direct the rostering program through the incident command structure/unified area command, most likely the logistics section.

- Explore the feasibility of incorporating rostering into existing response activities (e.g., personnel accountability and training programs), to improve efficiency of the activity.

- Develop mechanisms to encourage and facilitate employer participation, include rostering as part of predeployment planning for likely responders.

- Standardize interim reports to the incident command structure and participating organizations, to maximize utility of the collected information.

Two key rostering issues included (1) the number of paper rostering forms requiring input and (2) the creation of an online system for field input. Initial estimates placed the number of expected rostering forms to be between 3,500 and 10,000, but in reality over 55,000 rostering forms were collected. Given the volume of workers to be rostered and the limited opportunities to interact with them, paper-based forms were utilized as the primary data collection mechanism. A web-based roster input system was developed to provide an alternative means to complete rostering and to reduce data entry demands associated with the paper forms. Unfortunately, only a small number of forms were collected via the online system. This was disappointing because of the level of effort required to design and implement the online system, but the materials may be preserved for future events. The high percentage of missing e-mail addresses may indicate low computer/Internet use in this population, which may help explain the low usage of the online roster form. Additional barriers to use of the electronic form should be determined, because having a large volume of paper forms makes data entry and utilization quite slow. Electronic data collection mechanisms such as hand-held devices should be explored so that data can be collected and used faster.

To facilitate rostering and management of collected data, consideration should be given to creating financial vehicles that can be utilized on demand, such as preapproved but minimally funded contracts with vendors that can be quickly activated during response operations. 


\section{NEXT STEPS}

NIOSH is sponsoring an interagency work group that, over the past two years, has been developing a coordinated approach to responder health monitoring and surveillance. The work group consists of representatives of many federal, state, and local government agencies and responder groups. The product of the work group contains two main sections: (1) one that includes guidance and recommendations for the predeployment, deployment, and post-deployment stages and (2) one that provides links to relevant documents and examples of materials that could be used in a response (e.g., surveys and standardized questionnaires, checklists, databases, and software programs). Among the various areas addressed are Health Screening, Rostering, Training, Credentialing, Exposure Assessment and Controls, Medical Monitoring, and Medical Surveillance. Responder safety and health is addressed in this document systematically to ensure that only medically cleared, trained, properly equipped personnel are selected for deployment, their work environment and health are effectively monitored and surveilled throughout the event, and provisions are made for post-event health monitoring and surveillance where indicated. The guidance provides a comprehensive set of strategies and tactics for enhancing the safety and health of responders. This will help managers, medical personnel, and health and safety representatives prepare thoroughly before an event and help ensure worker health and safety during and following an event. A draft of this document was made available for public comment earlier this year [NIOSH 2011]. 


\section{References}

ATSDR [2007]. Rapid Response Registry [https://www.rapidresponseregistry.org/. Date accessed: May 2, 2011.

BLS [2011]. Standard Occupational Classification. Washington, DC: U.S. Department of Labor, Bureau of Labor Statistics [http://www.bls.gov/soc/]. Date accessed: August 25, 2011.

CDC [2009]. Prevalence and Trends Data: Tobacco Use, 2009. Behaviorial Risk Factor Surveillance System [http://apps.nccd.cdc.gov/brfss/list.asp?cat=TU\&yr=2009\&qkey=4396\&state=All]. Atlanta, GA: Centers for Disease Control and Prevention. Date accessed: May 20, 2011.

CDC [2008, September 3]. Public Health Assessment and Surveillance after a Disaster. CDC Emergency Preparedness and Response [http://emergency.cdc.gov/disasters/surveillance/]. Atlanta, GA: U.S. Department of Health and Human Services, Centers for Disease Control and Prevention. Date accessed: May 2, 2011.

NIEHS [2011]. Gulf Long-Term Follow-Up Study for Oil Spill Clean-Up Workers and Volunteers. NIEHS GuLF Study [http://nihgulfstudy.org/]. Research Triangle Park, NC: U.S. Department of Health and Human Services, National Institutes of Health, National Institute for Environmental Health Sciences. Date accessed: May 2, 2011.

NIOSH [2011, February 4]. Emergency Responder Health Monitoring and Surveillance. NIOSH Docket 223 [http://www.cdc.gov/niosh/docket/review/docket223/]. Cincinnati, OH: U.S. Department of Health and Human Services, Centers for Disease Control and Prevention, National Institute for Occupational Safety and Health. Date accessed: May 2, 2011.

NIOSH [2010, July 19]. Procedure for Recruiting Volunteers for Investigative Studies from the NIOSH Deepwater Horizon Roster. NIOSH Deepwater Horizon Response [http://www.cdc.gov/ niosh/topics/oilspillresponse/recruiting.html]. Cincinnati, OH: U.S. Department of Health and Human Services, Centers for Disease Control and Prevention, National Institute for Occupational Safety and Health. Date accessed: May 17, 2011.

U.S. Census Bureau [2011, August 17]. North American Industry Classification System [http://www.census.gov/eos/www/naics/]. Date accessed: August 25, 2011.

Unified Area Command [2010, July 6]. Administration-Wide Response Summary to the Deepwater BP Oil Spill, July 6, 2010. RestoreTheGulf.gov [http://www.restorethegulf.gov/release/2010/07/06/ administration-wide-response-summary-deepwater-bp-oil-spill]. Date accessed: August 10, 2011. 


\section{Appendix A: Roster Form}

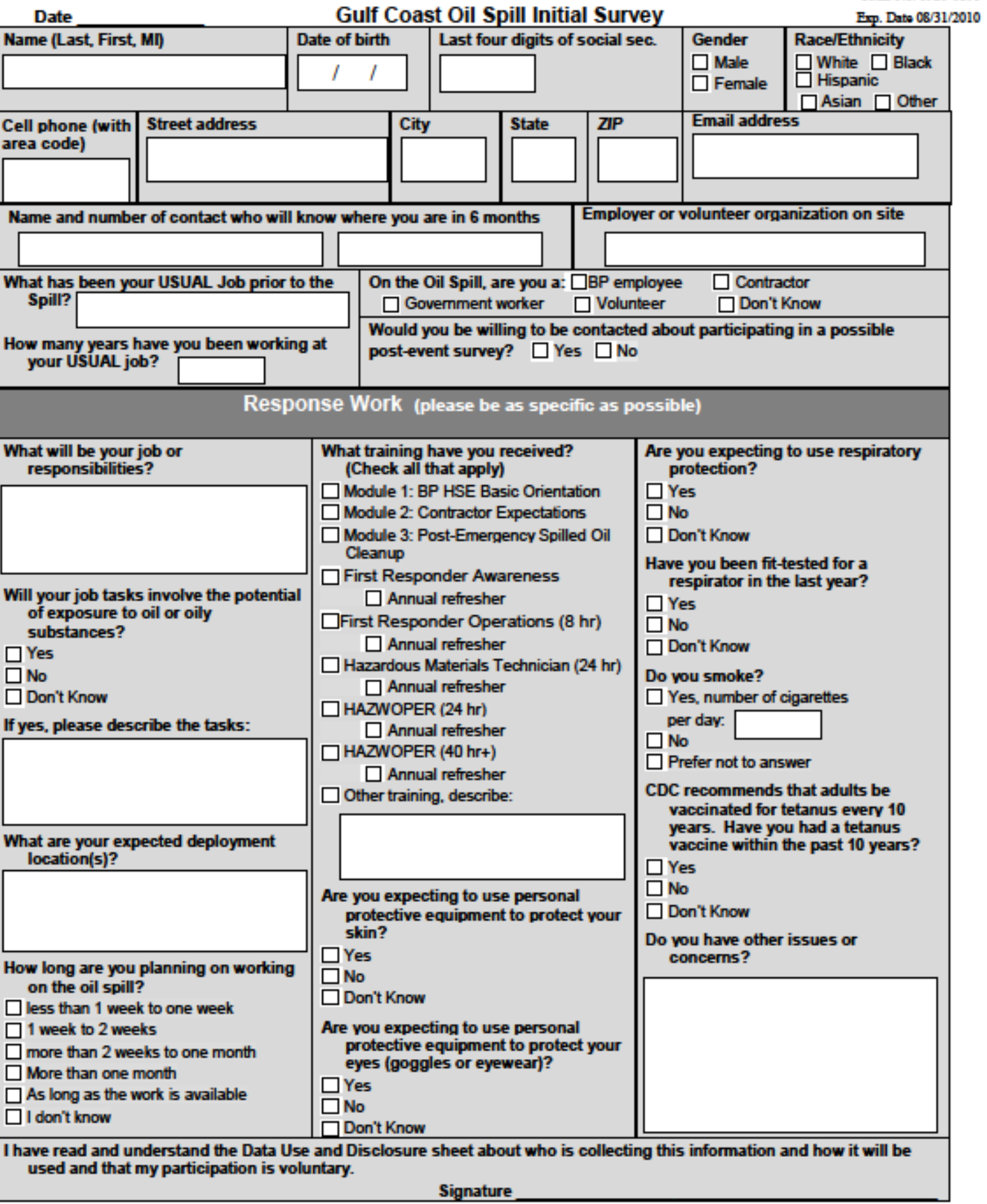

Public roporting burden of this collection of information is ostimsatod to arvarge 15 minutes per rouponse, inchuding the fime for reviouing instructions, searching existing data sourcer, gethering and maintrining the data needed, and completing und roviering the colloction of information. An agency maxy mot condact or sponsor, and a person is

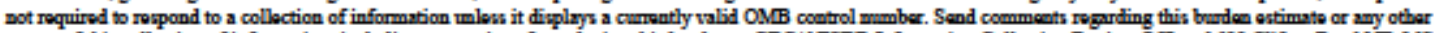
aspect of this collaction of information, including suggestions for rectucing this burden to CDC/ATSDR Information Collection Roviou Office, 1600 Clifton Rosd NE, MS D-74, Atlomta, Goorgin 30333; ATTN: PRA (0920-XX0XX). 


\section{Appendix B: Data Use and Disclosure Sheet}
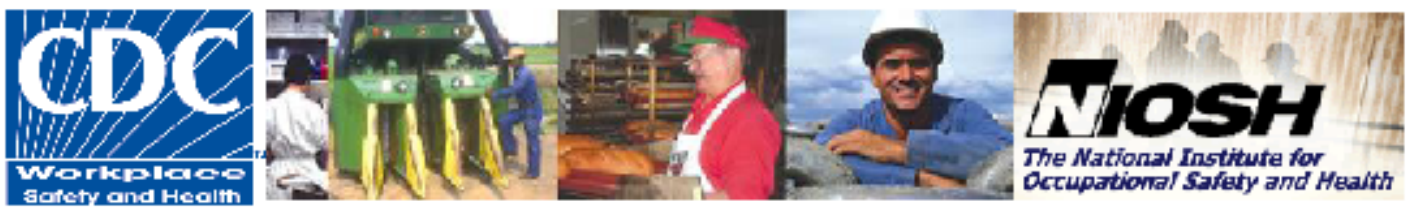

NIOSH is part of the Centers for Disease Control and Prevention (CDC)

in the Department of Health and Human Services. CDCANIOSH is the federal agency that evaluates and makes necommendations for the prevention of work-related injury and illness.

\section{DATA USE AND DISCLOSURE}

\section{Why is NIOSH here at the site of the Gulf Oil Spill?}

- We would like to monitor potential health effects workers involved in cleanup of an oil spill may experience so we can help protect them in the future.

- We have experts who routinely conduct these surveys of employees and employers.

\section{Why is this evaluation being done?}

- We know that workers may be potentially exposed to things in an oil spill cleanup: such as oils, volatile organic compounds, polyaromatic hydrocarbons, diesel fumes, heat, noise, and heavy lifting.

- We know that training will belp provide information to workers about these exposures, and we are interested in what training workers receive.

- We want to gather information from workers involved in cleanup, so that after cleanup is over, we can see if workers experienced any symptoms related to the oil spill work. Oil spill exposures may cause some workers to experience symptoms like skin rash, throat initation and cough, and back pain. We do not know if these synmptoms will occur or if they do, what will be the extent of these symptoms. We want to learn as much as we can in order to reduce symptoms now and in the future.

- Documenting symptoms in this incident may provide information that NIOSH can use to protect the health of workers in this clean up and in future clean-up efforts.

\section{Which employees does NIOSH want to evaluate?}

- NIOSH would like to evaluate ALL of the clean-up workers so that we can record any illness, injury, or stress that is occurring

\section{Will your answers be private?}

- Although the questionnaires will ask for personal information, it will only be used so that we can follow up with you, but ONLY group data will be reported.

- Participation in this survey is voluntary. You will decide whether you want to provide us with this information. You are free to choose not to answer these questionnaires. It is up to you.

- With your permission, NIOSH is allowed to collect and keep information about you, including your results from this questionnaire, because of two laws passed by Congress. These laws are:

1. The Public Health Service Act (42 U.S.C 241)

2. The Occupational Safety and Health Act (29 U.S.C. 669)

- If the information we are collecting is maintained and retrieved by personal identifiers, such as your name, it will become part of the CDC record system, maintained under the federal Privacy Act, and we will protect it to the extent allowed by law. We are requesting the last four digits of your Social Security Number so we can make sure to differentiate you from others with similar names. Again you are free to choose not to provide this information.

- You should know, however, that there are limited conditions under the Privacy Act when we could be authorized to release this information to outside sources. These conditions under which we might release this information are listed on Page 2 (the Privacy Act)

What will be the result of this evaluation?

- NIOSH will provide a final written report through CDC to BP, its contractors, the workers, and federal and state government agencies. This report will not contain individual information and will be available to the public.

Contact: Renée Funk, NIOSH. 404-498-GULF (4853), CDCNIOSHGULFWORKER@CDC.GOV 


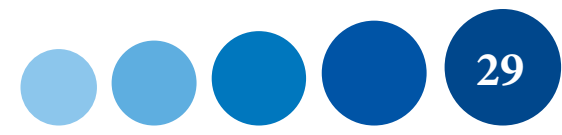




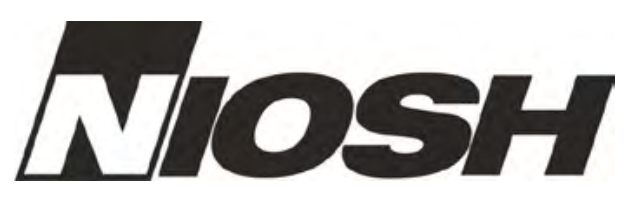

Delivering on the Nation's promise: safety and health at work for all people though research and prevention

To receive NIOSH documents or more information about occupational safety and health topics, contact NIOSH at

1-800-CDC-INFO (1-800-232-4636)

TTY: 1-888-232-6348

email: cdcinfo@cdc.gov

or visit the NIOSH Web site at www.cdc.gov/niosh.

For a monthly update on news at NIOSH, subscribe to

NIOSH eNews by visiting www.cdc.gov/niosh/eNews.

DHHS (NIOSH) Publication No. 2011-175

SAFER • HEALTHIER • PEOPLE ${ }^{\text {TM }}$ 